\title{
Teaching for breadth and depth of vocabulary knowledge: Learning from explicit and implicit instruction and the storybook texts
}

\author{
David K. Dickinson ${ }^{\mathrm{a}, *}$, Kimberly T. Nesbitt ${ }^{\mathrm{b}}$, Molly F. Collins ${ }^{\mathrm{a}}$, Elizabeth B. Hadley ${ }^{\mathrm{c}}$, \\ Katherine Newman ${ }^{\mathrm{a}}$, Bretta L. Rivera ${ }^{\mathrm{a}}$, Hande Ilgez ${ }^{\mathrm{d}}$, Ageliki Nicolopoulou ${ }^{\mathrm{e}}$, \\ Roberta Michnick Golinkoff ${ }^{\mathrm{f}}$, Kathy Hirsh-Pasek ${ }^{\mathrm{g}}$ \\ a Vanderbilt University, United States \\ ${ }^{\mathrm{b}}$ University of New Hampshire, United States \\ ${ }^{\mathrm{c}}$ University of South Florida, United States \\ d Bilkent University, Ankara, Turkey \\ e LeHigh University, United States \\ ${ }^{\mathrm{f}}$ University of Delaware, United States \\ ${ }^{g}$ Temple University, United States
}

\section{A R T I C L E I N F O}

Article history:

Received 1 May 2017

Received in revised form 13 July 2018

Accepted 17 July 2018

Available online 12 February 2019

\section{Keywords:}

Book reading

Preschool classrooms

Vocabulary instruction

Professional development

\begin{abstract}
A B S T R A C T
This paper reports results from two studies conducted to examine word learning among preschool children in group book reading while we developed a scalable method of teaching words during book reading. We sought to identify factors that fostered both depth and breadth of learning by varying the type of information children heard about words while holding exposures constant. We also asked whether prior word knowledge affects children's learning across our different instructional approaches. In Study 1 we evaluated pre-post gains from two types of explicit instruction (Didactic and Conceptual), an implicit instructional approach (Review), and repeated Exposure. For all three instructed conditions growth in receptive knowledge (our measure of breadth) was statistically equivalent when compared to control $(d=0.43)$ and exposure words $(d=0.41)$. In Study 2, words were taught using an augmented explicit approach and through repeated exposure. Moderate and statistically significant growth in receptive knowledge was found when comparing instructed to control words $(d=0.48)$ and large effects were found with an expressive task measure of depth of knowledge $(d=1.19)$. There also was evidence of learning from exposure. Children's vocabulary knowledge moderated learning gains. In Study 1 children with limited knowledge of vocabulary ( $0.75 \mathrm{SD}$ below the group mean) learned fewer words than others. In Study 2, pre-test vocabulary knowledge moderated gains on the expressive measure for directly taught words and gains on the receptive measure for words taught through exposure. Thus, when words were intentionally taught, all children except those with the weakest initial knowledge acquired the initial lexical representations captured by the receptive measure at a similar rate. Those with stronger vocabulary more quickly acquired initial representations from exposure alone and deeper knowledge when they received intentional instruction. We conclude that teachers can build depth and breadth of vocabulary knowledge by combining intentional instruction of target words with repeated use of varied words by reading books multiple times and instructional comments that include use of novel words.
\end{abstract}

(c) 2019 Elsevier Inc. All rights reserved.

\footnotetext{
is This research was conducted as part of award \#R305A110128 from the Institute for Education Sciences, U.S. Department of Education to Vanderbilt University, Temple University, the University of Delaware, and Lehigh University. The views expressed are those of the authors. We thank the teachers who opened their classrooms to us and worked with us and the coaches who were instrumental in the success of our project.

* Corresponding author.
}

\section{Using book reading to teach for breadth and depth of vocabulary}

Unless children know what the word "urgent" means, they will not understand why the protagonist in the story acted hastily to deliver medicine to his grandmother or why the mother had to take that important call even when she was in the middle of a meeting. If readers do not know the words in the story, they cannot read with full meaning. Such is the case for many children who come from 
low-income homes and homes where English is not the home language (Farkas \& Beron, 2004; Mancilla-Martinez \& Lesaux, 2011; NCES, 2015). Many children lack the broad and deep vocabulary that prepares them to be strong readers. Young children who are at least familiar with a large number of words, often termed vocabulary breadth, have stronger reading comprehension skills in the primary grades (Dickinson \& Porche, 2011; NICHD ECCRN, 2005; Storch \& Whitehurst, 2002; Walker, Greenwood, Hart, \& Carta, 1994). Those who also have deep knowledge of words, such that they can use a word in multiple contexts and provide a definition of it, enjoy better reading comprehension (Ouellette, 2006; Proctor, Silverman, Harring, \& Montecillo, 2012).

Ensuring that all children acquire both a broad and deep vocabulary is challenging. Some children come to school with strong language skills and can quickly learn new words (Munson, Kurtz, \& Windsor, 2005). They rapidly benefit from opportunities to learn words when teachers read books or tell stories. Children with weaker skills grasp new words less quickly (Blewitt, Rump, Shealy, \& Cook, 2009; Cain \& Oakhill, 2011; Penno, Wilkinson, \& Moore, 2002; Silverman \& Crandell, 2010). This divergent pattern of the "rich getting richer" is referred to as the "Matthew Effect" (Stanovich, 1986). This has often been framed as a problem to be overcome (e.g., Hindman, Erhart, \& Wasik, 2012), because children with the greatest needs fall farther behind their peers. One way to address this is to reduce the number of words taught and increase the intensity of instruction, but this risks depriving more able learners opportunities to learn. In the context of using book reading to large groups, this effect might better be interpreted as describing a reality of language learning that could be used strategically to maximize the learning opportunities of all children. Studies of word learning in one-to-one interactions in homes (Weizman \& Snow, 2001) and classrooms (Dickinson \& Porche, 2011 ) show that children acquire words from hearing them used in meaningful contexts. In classrooms, adroit language learners might similarly benefit. Thus, explicit vocabulary instruction may benefit all, including less skilled language learners. Exposure to many novel words through less intensive methods (e.g., rereading books, talking about text) might benefit all, but be particularly useful to those who are more able to learn in group book reading, a context that places a high demand on the ability to construct meaning purely through language.

Here we report results from two studies. Our program of research was designed to understand how children acquire initial familiarity with many word meanings (breadth of knowledge) and then more detailed word understanding (depth of knowledge) and to devise an effective method of teaching new words efficiently. The overall goal of our program of research is to combine teacher-directed play with book reading. In the current studies after the book readings children engaged in unstructured play, a form of play we anticipated would not result in learning of specific words (Weisberg, Hirsh-Pasek, Golinkoff, Nicolopoulou, \& Dickinson, 2015). In a subsequent study we confirmed that hypothesis by comparing unstructured play with play guided by a teacher and found that teacher-guided, but not unstructured play, supported word learning (Toub et al., 2018).

In the current studies we sought to understand word learning during book reading in preschool classrooms that occurred as a result of explicit instruction that included word definitions and picture references, implicit instruction that occurred as teachers commented on story events, and incidental exposure that occurred as children listened to stories. We hypothesized that book reading might support both initial surface learning of words from mere exposure and deeper knowledge acquired from different types of intentional instruction, that explicit and incidental teaching as well as simple exposure would result in learning, and that we would find Matthew Effects. We systematically explored learning that resulted from direct instruction of word meanings, of explanations about story content that did not directly deal with voabulary, and that occurred as novel words are heard as stories were read. To study effects of multiple features of book reading on word learning we used a receptive measure of breadth of learning and a productive measure of depth of learning.

\subsection{Depth and breadth of word knowledge}

Breadth of knowledge is an approach to teaching and measuring vocabulary that focuses on how many words are learned, rather than how well those words are learned (Anderson \& Freebody, 1981; Hadley \& Dickinson, 2018; Hadley, Dickinson, Hirsh-Pasek, Golinkoff, \& Nesbitt, 2016) Instructionally, a breadth approach concentrates on teaching as many words as possible, rather than building extensive knowledge for individual words. This approach supports a "fast-mapped" knowledge of words (Carey, 1978), in which a few exposures lead to a relatively shallow understanding of words, including some phonological and syntactic information, but relatively minimal semantic knowledge (Estes, Evans, Alibali, \& Saffran, 2007; Yuan \& Fisher, 2009). Additional knowledge of words can then be built on this fast-mapped "platform" through additional incidental exposure.

\subsubsection{Word knowledge and reading comprehension}

Depth of knowledge refers to a focus on the quality of word knowledge, with instructional efforts focused on building more extensive word knowledge for a relatively smaller pool of words (i.e., McKeown \& Beck, 2014). Here, we use Perfetti's (2007) Lexical Quality Hypothesis (LQH), a theory of how word knowledge facilitates reading comprehension, to conceptualize depth. The LQH sees word knowledge as a continuum, ranging from low to high along the dimensions of (1) form (orthographic, phonological, and grammatical information) and (2) meaning (semantic information). High lexical quality representations are built over many encounters with words, and include accurate representations of the word's spelling and sound and precise, flexible semantic knowledge. Low lexical quality representations are those in which the word form is not consistently produced, or meaning is limited to a single context. In addition, the LQH sees the ability to quickly retrieve and use a word in the proper context, thereby facilitating comprehension, as the outcome of high-quality word knowledge. The ability to use words in context may be an especially important marker of depth for preschoolers, whose knowledge of words is less decontextualized than older children (Snow, Cancino, De Temple, \& Schley, 1991).

Drawing on the key constituents of the $\mathrm{LQH}$, we define depth as knowledge of form, meaning, and use (Nation, 2013). While the LQH is a theory of reading mainly validated with older children, preschool children's lexical quality has been shown to predict reading outcomes in first grade (Murphy \& Farquharson, 2016), demonstrating its applicability even to young children. As the present study supports oral, rather than written, language, we use "form" to refer here to words' phonological and grammatical representations, rather than orthographic aspects (Perfetti \& Starfur, 2014). Given this conceptualization of depth, instruction seeking to build high quality representations should foster phonological, semantic, and pragmatic knowledge of words.

\subsubsection{Measuring depth of knowledge}

The present study assesses depth of knowledge by using a definition task, in which a child is asked, "What do you know about [target word]?" For this task children must recognize the word's form, as supplied by the tester, and retrieve associated information about its meaning and use. The definition task therefore assesses for the ability to accurately retrieve word identities, the hallmark of 
high-quality word knowledge according to the LQH (Perfetti, 2007). We further operationalize the LQH here by giving a point for each unit of semantic and contextual information supplied by the child. This scoring reflects the fact that high-quality semantic knowledge includes rich information gleaned over multiple encounters with a word, including information about a word's function, perceptual qualities, and/or typical contexts of use. As each word can have a wide range of possible scores, the definition task is also in keeping with the LQH's conception of word knowledge as lying on a continuum, in which lexical quality can range from low to high.

Researchers commonly ask whether children acquire new words from contrasting instructional methods. Sometimes knowledge is assessed using only measures of shallow learning (e.g., point to a picture, use a word when shown) (Brabham \& Lynch-Brown, 2002; Gonzalez et al., 2010; McLeod \& McDade, 2011; Roskos \& Burstein, 2011). Others who have studied learning in preschool classrooms have included breadth and depth measures (Coyne, McCoach, Loftus, Zipoli, \& Kapp, 2009; Sénéchal, 1997; Wasik, Bond, \& Hindman, 2006). McLeod and McDade (2011) specifically examined acquisition of initial shallow representations). In Study 1 we assess breadth and in Study 2 we examine breadth and depth of knowledge. This shift is a by-product of our iterative approach; after Study 1 we realized our need for information about the depth of knowledge.

\subsection{Using book reading to teach words}

Book reading is the most consistent gateway to vocabulary learning (National Early Literacy Panel, 2009), with a fixed effect size of 0.47 . In a review of 31 studies of book reading, Mol, Bus, and de Jong (2009) found an average effect size of $d=0.62$ on productive vocabulary from book reading. Marulis and Neuman (2010) reviewed 67 preschool vocabulary interventions and found moderately strong effects of $g=0.88$. These meta-analyses combine many approaches to using book reading so offer little insight regarding the benefits of any particular approach.

Opinions vary as to whether interventions should be extensive and shallow, or more focused on a handful of words to build deeper knowledge, with studies examining learning amount in preschool children (Hadley et al., 2016), kindergarteners (Coyne, McCoach, \& Kapp, 2007; Coyne et al., 2009; McKeown \& Beck, 2014), first graders (Beck \& McKeown, 2007), and first grader through third graders (Biemiller \& Boote, 2006). Depth of knowledge has effects on reading distinct from breadth, suggesting that a focused approach may be beneficial (Nation \& Snowling, 2004; Ouellette, 2006; Tannenbaum, Torgesen, \& Wagner, 2006). Yet, many children enter school with small mental dictionaries and require a bounty of words and associated world knowledge to achieve strong outcomes. Those who enter school in the bottom quartile of vocabulary knowledge, for example, need to learn roughly 2000 additional root words if they are to approach the average word knowledge of entering peers while also keeping pace with their peers who continue to learn about 1000 new words a year (Biemiller \& Boote, 2006). We hypothesized that book reading can foster both breadth and depth.

\subsubsection{Explicit formal definitions}

Research has repeatedly demonstrated the utility of explicit definitions, with these findings being reported for preschool (Collins, 2010; Dickinson et. al., in press; Gonzalez et al., 2010; Hadley et al., 2016; Hadley, Dickinson, Hirsh-Pasek, \& Golinkoff, in press; Justice, Meier, \& Walpole, 2005; Neuman, Newman, \& Dwyer, 2011; Wasik, Hindman, \& Snell, 2016) and kindergarten through grade 3 (Biemiller \& Boote, 2006; Coyne, Kame'enui, Simmons, \& Harn, 2004; Coyne, McCoach, \& Kapp, 2007; Coyne, McCoach, Loftus, Zipoli, \& Kapp, 2009). Formal definitions quickly link a word to networks of knowledge. They often include categorical information (e.g., "a spear is a kind of weapon ") and may include information about the context within which the item is encountered (e.g. "a spear is a kind of weapon that knights used to fight with."). Some definitions reference taxonomic categories that carry with them information about catgory members (e.g., "a peach is a kind offruit"). Words taught in taxonomic categories are learned with relative ease, reflecting the fact that they tap into networks of knowledge (Hadley et al., in press; Neuman \& Dwyer, 2011).

Biemiller and Boote (2006) compared learning of words among kindergarten to second grade children from either simple exposure or learning when given definitions. Using a measure that required children to verbally define words, a measure of depth, they found that providing definitions created a $28 \%$ increase in learning relative to mere exposure to words. Coyne et al. $(2007,2009)$ also found improved learning when children were provided word meanings as compared to exposure alone.

Thus, definitions quickly build intial word representations that link to prior knowledge by accessing existing knowledge networks. They are well-suited for use during group book reading because the event can be structured to include didactice exchanges (e.g., as words are pre-taught) and teachers can use planned definitions with prompts such as pictures and gestures. However, definitions also have drawbacks. When used as a book is read or during a conversation they break the flow; when used spontaneously speakers may have trouble formulating accurate definitions; and some words, especially abstract terms (e.g., imagination), are hard to define clearly and quickly. Also, there is a limit to how many definitions one can insert into a book reading before listeners tune out. In the current studies we read books four times and teach using formal definitions for half the words in two readings and the other half in the other two readings.

\subsubsection{Questioning and commenting}

The contributions of questions and comments pitched at different levels of conceptual complexity have been explored in preschool classrooms. Effects of questioning was examined by Sénéchal (1997) in a study of three- and four-year olds. She compared teaching through exposure versus using questions. The questioning method resulted in larger growth than simple repeated reading, with gains 3.7 times larger on their expressive measure and 1.7 larger for their receptive measure. A study of book reading with four-year olds found that vocabulary gains were associated with conversations that posed questions and fostered analytic discussions (Dickinson \& Porche, 2011; Dickinson \& Smith, 1994). A study with Head Start children with language impairment by van Kleeck, Vander Woude, and Hammett (2006) revealed that children benefited from being asked a mixture of low level and inferential questions. Similarly, Blewitt, Rump, Sheely and Cook (2009) noted that when questioning by an adult moved from lower demand prompts to more challenging prompts, word learning increased. Studies using dialogic reading methods in which adults and children co-constructed a story when reading books increase adult questioning and have been found to foster story understanding and build depth of vocabulary knowledge (Mol et al., 2009; Mol, Bus, de Jong, \& Smeets, 2008).

Questions that pose high level queries have not always been found to be associated with language growth among preschoolaged children (Zucker, Justice, Piasta, \& Kaderavek, 2010). A partial replication of this finding came from an examination of book reading in Head Start classrooms. Children benefited when teachers supplied conceptually informative comments with a moderate level of challenge (e.g., giving word definitions, providing background information) (Barnes \& Dickinson, 2017; Barnes, Dickinson, \& Grifenhagen, 2017). Comments coded for the highest level of conceptual challenge were not associated with growth, possibly because they were too complex for children. Zucker also found that 
preschool children benefitted when teachers supplied extratextual talk that varied in conceptual complexity (Zucker, Cabell, Justice, Pentimonti, \& Kaderavek, 2013).

In our approach we shift from giving conceptually useful information and asking relatively low-inference questions toward asking increasingly high demand questions across the four readings.

\subsubsection{Knowledge of story events}

Another way that word learning may occur in the absence of explicit definitions is by hearing them used as part of descriptions of interesting events in a story. Pictures and the events being described can supply many clues about a word's meaning (e.g., "Holding his lance, the knight charged at the dragon."). Repeated reading of stories was associated with greater use of target words (Penno et al., 2002). This learning from context may be enhanced if teachers comment on events, providing missing background information or make explicit connections between events. In one of our conditions in Study 1 we directly evaluate the effectiveness of teaching by reviewing story events and in Study 2 we fold that strategy into our approach.

\subsubsection{Learning through exposure}

High quality books are a rich source of novel words that is more diverse than what is found in spoken language (Montag, Jones, \& Smith, 2015). But books vary in the language learning opportunities they provide. A study that compared effects of the Opening the World of Learning (OWL) (Schickedanz \& Dickinson, 2005) curriculum to practice as usual in Head Start classsrooms found that practice-as-usual teachers almost all used books with highly predictable texts whereas the OWL curriculum used sophisticated children's literature. The high quality literature had more total words and more varied types and teachers used more varied words and complex syntx when talking about them (Dickinson, Hofer, Barnes, \& Grifenhagen, 2014). Differences in the texts of books may be important because incidental use is the primary way children acquire a broad lexicon. They learn words during informal conversations in homes (Hoff, 2006; Hoff \& Naigles, 2002; Weizman \& Snow, 2001), as they reminisce about past events (Peterson, Jesso, \& McCabe, 1999) and in informal conversations with teachers in preschool classrooms (Dickinson \& Porche, 2011).

Children acquire and retain some knowledge of words after a single exposure during conversations that supply meaning through context (e.g., "give me the bice pen not the blue one.") (Carey, 1978, 2010; Dickinson, 1984). McLeod and McDade (2011) found that preschool-aged children can learn new words from hearing them used during a book reading, but they tested only single syllable words that mapped onto known concepts. Learning from exposure during book reading also has been found for kindergartners after two readings (Robbins \& Ehri, 1994) and among school-aged children (Oetting, Rice, \& Swank, 1995).

\subsection{Additional factors that affect word learning}

\subsubsection{Frequency of use}

Frequency of use of words is an important determinant of word learning (Dickinson \& Porche, 2011; Huttenlocher, Haight, Bryk, Seltzer, \& Lyons, 1991). Book reading research finds beneficial effects associated with hearing words multiple times. McLeod, for example, noted that hearing words 9 times as opposed to 3 times resulted in significantly more learning, with stronger effects on nouns than verbs (McLeod \& McDade, 2011). Coyne and his colleagues (Coyne et al., 2007; Coyne et al., 2009) used a word once with kindergarten children across three readings and found that children responded at chance levels; first graders in the same study showed initial learning for only 5.3\% of the words. Sénéchal (1997) read books one or three times to three-and four-year-olds and found no evidence of receptive or expressive knowledge after one reading, but found small equivalent gains in both receptive and expressive knowledge after three readings. Similarly, Biemiller and Boote (2006) reported that kindergartners learned $12 \%$ of the words to which they were only exposed when books were read four times, but they did not track how many times those same words were used in the texts. Frequency of use has been controlled in some vocabulary intervention studies (Blewitt et al., 2009; Collins, 2010; Coyne et al., 2007; Coyne et al., 2009; McLeod \& McDade, 2011; Penno et al., 2002), but not in others (Biemiller \& Boote, 2006; Brabham \& Lynch-Brown, 2002; Gonzalez \& Nelson, 2003; Neuman \& Dwyer, 2011; Roskos \& Burstein, 2011). We control the number of times children hear all words that we test.

\subsubsection{Word type}

The rate at which children learn words varies by the word type. Verbs are more difficult to learn than nouns (Gentner, 1982; McDonough et al., 2011). McLeod and McDade (2011) found fast mappings for roughly 30\% of taught words, with nouns being learned about $25 \%$ better than verbs. While form class affects learning, a more important distinction may be a word's imageability (Authors, 2009; Ma, Golinkoff, Hirsh-Pasek, McDonough, \& Tardiff, 2009). Analysis of word learning among four-year-olds revealed differences between concrete and abstract nouns (Hadley et. al., 2016; Authors, 2016a). That analysis divided verbs into concrete and abstract sets and found concrete nouns were learned faster than concrete verbs which, in turn, were learned faster than abstract nouns. Many prior intervention studies either have not controlled for or have not varied word type (Biemiller \& Boote, 2006; Blewitt et al., 2009; Gonzalez et al., 2010; Hargrave \& Senechal, 2000; Loftus, Coyne, McCoach, Zipoli, \& Pullen, 2010; Neuman \& Dwyer, 2011; Penno et al., 2002). To better understand how the type of word affects the breadth and depth of vocabulary learning, we use concrete and abstract nouns, verbs, and adjectives, and examine results for evidence of shallow and deep learning by word type. In both studies we take word type into account and include similar numbers of different types of words in different instructional conditions and in both the words we teach and those that serve as control words.

\subsubsection{Prior knowledge}

Children's pre-existing vocabulary knowledge affects their ability to acquire words. It affects speed of word learning when children only are exposed to words and when direct instruction is provided (Penno et al., 2002; Robbins \& Ehri, 1994; Sénéchal, Thomas, \& Monker, 1995). We controlled for students' prior knowledge of words to be taught, which is a weak means of controlling for prior knowledge, but was the only method available for this study.

\subsection{Overview of the present studies}

In Study 1 we explore the effects on word learning associated with supplying different types of information about word meanings. In Study 2 we examine breadth and depth of learning of taught words and of words that only were heard as stories were read. In both studies we control (1) the number of exposures to words; (2) the amount and type of information about word meanings provided, (3) references to pictures, and use of gestures; and (4) word type. In both studies we consider the effects on learning of chil-

\footnotetext{
1 We analyzed for word type effects, but do not report them because prior research has established their importance. These analyses are available from the authors upon request.
} 
dren's prior knowledge of vocabulary and use a within-subjects approach that controls for child demographic variables.

\section{Study 1}

In Study 1 we posed three research questions:

1. Does word learning vary according to the type of information children are provided about word meanings that we supply through three conditions (Review, Conceptual, and Didactic)?

2. Do children make greater gains on intentionally taught (Instructed) words compared to Exposure words that are not highlighted? And are greater gains made on Exposure words compared to Control words that are never heard?

3. Is word learning moderated by children's initial vocabulary knowledge?

Three experimentally tested book approaches to teaching words, - Review, Conceptual, and Didactic - were employed. The number of times children heard words read was constant across conditions. We hypothesized that children randomly assigned to the Didactic and Conceptual conditions would make larger vocabulary gains than children in the Review condition and that all instructional conditions would show more pre-post growth on Instructed than on Exposure or Control words. We also assessed learning that occurred as children were exposed to words during story readings. Each instructional condition included Exposure words.

We assessed learning by word type and hypothesized that children would learn concrete nouns better than other word types, as previous work has suggested (Authors, 2016a). We also examined effects of children's prior language levels and expected that children with lower initial vocabulary knowledge would not benefit as much as their peers with greater initial knowledge.

\section{Methods}

\subsection{Participants}

Participants were recruited from 27 preschool and prekindergarten classes serving high-risk children from low-income families. Ten were Head Start classrooms in the Mid-Atlantic region of the United States, and 17 were state pre-K classrooms in the Southern region of the United States. Approximately nine children per classroom participated. The average age for the 226 children in the study was 57.3 months ( $S D=4.9$ months) at the onset of the study. Based on teacher report, 15\% of the sample were English Language Learners (ELL). The sample was approximately $47 \%$ male. Fifty-four percent of children were African American, 25\% Hispanic, $14 \%$ Caucasian, and $7 \%$ were designated biracial or of another ethnicity. Of the $30 \%$ of parents who claimed that another language was spoken at home, $86 \%$ reported Spanish. Eighty percent of the mothers reported their highest levels of school attainment: $14 \%$ had some high school; 33\% had a high school diploma or graduate equivalency degree (GED); $14 \%$ had attended trade school; $11 \%$ had an associate's degree; $8 \%$ had a bachelor's degree; and 3\% had graduate degrees.

\subsection{Procedure}

The experiment was conducted between the end of January and the middle of March. All children were individually pre-tested and post-tested for vocabulary knowledge by trained research assistants within one week prior to and following the intervention. Children were randomly assigned to one of three conditions: 74 in Didactic, 76 in Conceptual, and 76 in Review. Half of the classrooms (46.5\% of the children) were randomly assigned to start with one story theme and half with the other. Books within each theme were counterbalanced. Intervention Specialists (IS) read to the same group of mixed-gender groups of three children in a quiet location outside the classroom for four consecutive days during the week. A tripod and video camera were positioned to capture the book readings. Instruction was delivered by Intervention Specialists (IS) who had prior teaching experience and were trained by the project. The ISs used scripted instruction to control for word frequency across conditions.

\subsubsection{Book and word selection}

Two thematically related books were read for each theme, a dragon theme (The Knight and the Dragon, (dePaola, 1980), Dragon for Breakfast (McMullen \& McMullen, 1990) and a farm theme (Farmer Duck (Waddell \& Oxenbury, 1991), and Pumpkin Soup (Cooper, 1998). All books were of comparable length and words being taught were depicted with equal frequency across books. Each book had a storyline that could be enacted by three to four children.

For each book, sixteen words were selected for direct teaching (Instructed words) and eight were heard only as Exposure words. Instructed and Exposure words included abstract and concrete nouns, verbs, adjectives, and spatial prepositions (see Appendix Table A1). Words were selected by referring to Biemiller's (2010) list of word difficulty, and the list of words deemed to be sophisticated words based on the list developed by Snow (Dickinson \& Tabors, 2001). Of the 64 words we taught 48 appeared on Biemiller's list and 58\% and were at least Level T2 (high priority words typically known by more advanced students by the end of second grade and not known by at-risk students); $85 \%$ were on the list of sophisticated words. Words were semantically and phonologically distinct from one another (see Table A2 for words listed by type).

\subsubsection{Play}

Following all readings, children played with replica props (e.g., a throne) that related to the story theme for ten minutes. Replica play props represented instructed concrete nouns or encouraged enactment of instructed verbs (e.g., a horse for the verb gallop). Adults did not intervene other than to maintain order.

\subsection{Book reading conditions}

Appendix Table A1 shows the presentation design. Children heard each word 12 times. Instructed words were heard four times as the text was read and eight times as part of instructional interactions. During two of the four readings meanings were taught directly. Set $\mathrm{A}(n=8)$ was instructed during readings 1 and 3 and set $\mathrm{B}(n=8)$ during readings 2 and 4 . We chose this approach because we believed that familiarity with the text might affect learning and because comprehension questions increased in difficulty across readings, and that might have an effect on word learning as well.

We also sought to determine if words were learned through incidental use, with Exposure words being included in each instructional condition. To see if children learned words through exposure eight Exposure words were included in each book. These words were heard 12 times across the four readings.

\subsubsection{Review condition}

Explicit definitions were not supplied in this condition and the IS did not point to the pictures when words were used. The teacher used the word incidentally twice after the word appeared in the text. 
First, the knight and the dragon charged at each other. Oh look! They missed each other. See what happened to the dragon [point] and to the knight [point]. Do you think they will try to charge at each other again? Let's see what happens.

In the discussion that followed the reading, the IS and children recalled the story while looking at pictures. The words were used two times. The IS did not define the words or ask children to use them.

Who can we see on this page? Yes, here is the duck fetching the cow from the pouring rain. (Point to farmer) And here is the farmer, nice and dry in the house. He never fetches the animals himself, he makes poor duck do all the work.

\subsubsection{Conceptual condition}

This condition provided children as much information about the word's meaning as possible while holding the number of uses of the word constant. The first time a word was taught (i.e., day one or two) during the reading, definitions were provided and gestures were suggested or modeled. Contrastive information was also supplied (it was "behind" the knight; not "in front of him.") when feasible. Different tenses were used when verbs were introduced to highlight their syntactic category. Here is the instruction during a first reading,

Let's pretend I am the dragon and I am looking for my book. It is hidden under other things in the box so I am rummaging around - I have to move things to find it [act out]. Show me how you might rummage around and look for a toy you want to play with.

The second day a word was taught (i.e., day three or four) additional conceptual information was given while referring to the picture. This time children were encouraged to use the word.

The dragon is lucky his body is covered with these hard little plates [point to them in full-body picture]. The dragon is covered in. ...[wait] scales. What do they feel like? [Responses] Right, the scales are hard. And how can they help the dragon? [Responses] Yes, they will protect the dragon's body when it fights the knight or another animal.

After each reading, additional instruction was provided to reinforce conceptual knowledge. The commentary related to specific story events but did not review their sequence. Children were asked to act out verbs, and comments referenced props or pictures. On both days, children were encouraged to use the word.

When the knight and the dragon tried to fight they ran at each other very fast like this [show it with figures]. They... [wait for child response]. Everyone say charged! They charged at each other very fast, but they missed hitting each other [act out with toys].

\subsubsection{Didactic condition}

Children were given formal definitions for words without reference to the storyline. When a word was first taught (i.e., day one or two), children were told the definition of the words before the reading. When a word was read, it was defined, and children were asked to repeat it. On the second instance of instruction, children were asked to produce the word and the definition, during the book reading. For example, they might hear, "Say return. What does that mean? Yes, it means to come back to a place where you have been before." The definition was repeated and the children were then asked to repeat the word themselves "Return is to come back to a place where you have been before. Say return."

\subsubsection{Training and fidelity}

Intervention Specialists were trained by the research team to deliver all three approaches. Training and fidelity consisted of a group training meeting in which ISs reviewed scripts and practiced using materials with each other; an on-site practice session at non-participating preschools in which research team members demonstrated approaches with small groups of children; and follow-up sessions with small groups. ISs practiced methods and received feedback. ISs reached high levels of fidelity on all approaches prior to implementation. Analysis of videotapes of the first and fourth readings of the Conceptual and Didactic conditions found fidelity to be greater than $96 \%$ agreement for all ISs. Fidelity on the first reading of the Review approach was $100 \%$ agreement.

\subsection{Measures}

Our measure of learning that we interpret as reflecting improving breadth of vocabulary knowledge was a receptive test of understanding of instructed words. It was modeled after the Peabody Picture Vocabulary Test - 4 (PPVT-4) (Dunn \& Dunn, 2007) and was administered at pretest and posttest (Blewitt et al., 2009; Penno et al., 2002). Children selected a response from three pictures: a correct referent, a thematically related foil (e.g., fish for the instructed word pond) and a conceptually related foil (e.g., stream for the instructed word pond). Pictures of the instructed words were different from those used in the books to assess transfer from the original word to new instances. Four practice items depicting familiar objects were used at the beginning of the test to ensure that children understood the task. The test for the dragon theme consisted of 54 items, including 31 Instructed words, 15 Exposure words, and 8 Control words. The farm theme tested 53 items, including 30 Instructed words, 15 Exposure words, and 8 Control words.

\section{Results}

\subsection{Descriptive statistics and baseline equivalence}

Pretest and posttest descriptives by experimental book reading condition and level of instruction are provided in Tables 1 and 2 . As with all analyses conducted, to test for baseline equivalence, we conducted a series of multilevel regression models (Raudenbush \& Bryk, 2002), with robust estimates of standard errors in SPSS version 23 that examined the association between the dependent variable of pretest vocabulary scores and book reading condition. Models accounted for the nesting of study children within classrooms and schools and controlled for storybook theme. Analyses indicated baseline equivalence across the three conditions for instructed, exposure, and control vocabulary words, $p s>0.194$.

Across condition, children at pretest knew a higher proportion of Instructed words compared to Exposure words, $\gamma=-0.06$, $S E=0.01, p<0.001$, or Control words, $\gamma=-0.08, S E=0.01, p<0.001$. Post-hoc pairwise comparisons with Fisher's Least Significant Difference (LSD) adjustments also indicated that scores for Control words were marginally higher than for Exposure words at pretest $(p=0.051)$. Children's pretest vocabulary knowledge was included as a covariate in all subsequent analyses.

\subsection{Book reading experimental condition}

We first tested for effects of the three experimental conditions. The following multilevel regression model was employed to test for effects on vocabulary knowledge at posttest:

$$
\begin{gathered}
\text { Posttest }_{\mathrm{ijk}}=\gamma_{000}+\gamma_{100} * \text { Pretest }_{\mathrm{ijk}}+\gamma_{010} * \text { Conceptual }_{\mathrm{jk}} \\
+\gamma_{020} * \text { Review }_{\mathrm{jk}}+\gamma_{001} * \text { Theme }_{\mathrm{k}}+\mathrm{U}_{00 \mathrm{k}}+\mathrm{U}_{0 \mathrm{jk}}+\mathrm{r}_{\mathrm{ijk}}
\end{gathered}
$$


Table 1

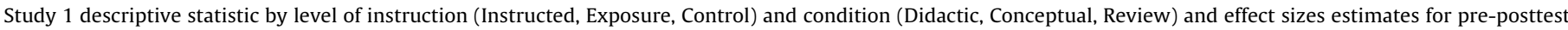
differences and experimental condition.

\begin{tabular}{|c|c|c|c|c|c|}
\hline \multirow[t]{2}{*}{ Source } & \multicolumn{2}{|l|}{ Mean $(S D)$} & \multicolumn{3}{|l|}{ Cohen's $d$ effect sizes } \\
\hline & Pretest & Posttest & Pre-posttest differences & Compared to review & Compared to conceptual \\
\hline \multicolumn{6}{|l|}{ Instructed } \\
\hline Review ( $n=76$ children $)$ & $0.56(0.13)$ & $0.62(0.13)$ & $0.47^{* *}$ & - & -0.10 \\
\hline Didactic $(n=74)$ & $0.55(0.13)$ & $0.63(0.13)$ & $0.63^{* *}$ & 0.15 & 0.04 \\
\hline Conceptual $(n=76)$ & $0.55(0.13)$ & $0.63(0.14)$ & $0.56^{* *}$ & 0.10 & - \\
\hline \multicolumn{6}{|l|}{ Exposure } \\
\hline Review & $0.47(0.14)$ & $0.51(0.18)$ & $0.30^{* *}$ & - & -0.23 \\
\hline Didactic & $0.50(0.15)$ & $0.53(0.14)$ & $0.23^{* *}$ & 0.04 & -0.22 \\
\hline Conceptual & $0.47(0.16)$ & $0.55(0.16)$ & $0.52^{* *}$ & 0.23 & - \\
\hline \multicolumn{6}{|l|}{ Control } \\
\hline Review & $0.50(0.19)$ & $0.52(0.20)$ & 0.16 & - & 0.03 \\
\hline Didactic & $0.49(0.19)$ & $0.53(0.20)$ & $0.22^{* *}$ & 0.01 & 0.04 \\
\hline Conceptual & $0.53(0.19)$ & $0.53(0.20)$ & 0.04 & -0.03 & - \\
\hline
\end{tabular}

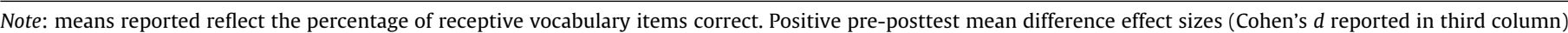

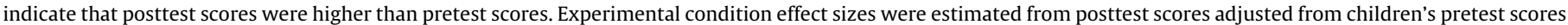

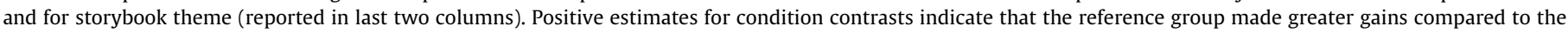

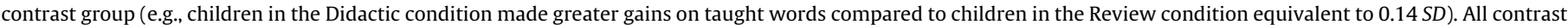
tests of experimental difference were non-significant.

*** $p<0.01$.

Table 2

Descriptive statistic and effect sizes estimates by level of instruction (Instructed, Exposure, and Control) for Study 1 (Top Panel) and Study 2 (Bottom Panel).

\begin{tabular}{|c|c|c|c|c|c|}
\hline \multirow[t]{2}{*}{ Source } & \multicolumn{2}{|l|}{ Mean (SD) } & \multicolumn{3}{|l|}{ Cohen's $d$ effect sizes } \\
\hline & Pretest & Posttest & Pre-posttest differences & Compared to control & Compared to exposure \\
\hline \multicolumn{6}{|l|}{ Study 1} \\
\hline \multicolumn{6}{|l|}{ Receptive vocabulary } \\
\hline Instructed ( $N=226$ children $)$ & $0.55(0.13)$ & $0.63(0.14)$ & $0.55^{* *}$ & $0.43^{* *}$ & $0.41^{* *}$ \\
\hline Exposure & $0.48(0.15)$ & $0.53(0.16)$ & $0.35^{* *}$ & 0.08 & - \\
\hline Control & $0.50(0.19)$ & $0.52(0.20)$ & $0.14^{*}$ & - & -0.08 \\
\hline \multicolumn{6}{|l|}{ Study 2} \\
\hline \multicolumn{6}{|l|}{ Receptive vocabulary } \\
\hline Instructed $(N=83)$ & $0.37(0.13)$ & $0.53(0.18)$ & $1.07^{* *}$ & $0.48^{* *}$ & 0.19 \\
\hline Exposure & $0.46(0.23)$ & $0.54(0.24)$ & $0.30^{* *}$ & $0.22^{+}$ & - \\
\hline Control & $0.46(0.17)$ & $0.49(0.19)$ & 0.14 & - & $-0.22^{1}$ \\
\hline \multicolumn{6}{|l|}{ Expressive vocabulary } \\
\hline Instructed $(N=82)$ & $0.11(0.17)$ & $0.42(0.41)$ & $1.01^{* *}$ & $1.19^{* *}$ & $0.63^{* *}$ \\
\hline Exposure & $0.33(0.37)$ & $0.37(0.43)$ & $0.10^{1}$ & $0.37^{*}$ & - \\
\hline Control & $0.18(0.29)$ & $0.20(0.23)$ & 0.08 & - & $-0.37^{*}$ \\
\hline
\end{tabular}

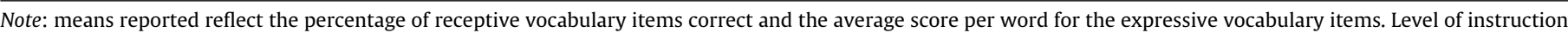

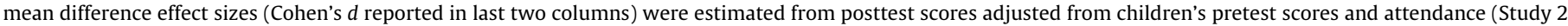

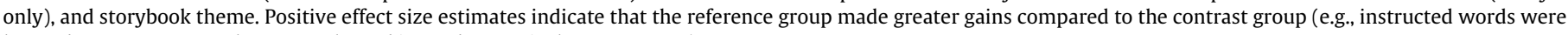
learned at a rate greater than control word in Study 1 equivalent to 0.43 SD).

${ }^{*} p<0.05$.

$p<0.01$.

$+p<0.10$.

There were three nesting levels; children $_{\mathrm{ijk}}$ were nested within reading groups $s_{\mathrm{jk}}$ which were nested within classrooms $\mathrm{k}_{\mathrm{k}}$. We entered condition effect into the model at the reading group-level. The reading group condition variable was dummy coded with the Didactic condition as the reference group, which was compared to the Conceptual $\left(\gamma_{010}\right)$ and Review $\left(\gamma_{020}\right)$ conditions. Children's pretest vocabulary scores $\left(\gamma_{100}\right)$ were included as a child-level covariate. Other child level factors were controlled by virtue of the fact that the outcome was a within-individual variable. Because all children in the same class received the same book theme, theme was entered at the classroom level $\left(\gamma_{001}\right)$ with the farm theme serving as the reference group.

Effects of condition were estimated while controlling for a significant positive effect of pretest scores (Instucted $\gamma_{100}=0.63$, $S E=0.06 ; \quad$ Exposure $\gamma_{100}=0.46, \quad S E=0.07 ; \quad$ Control $\gamma_{100}=0.32$, $S E=0.06$ ), thus the effect can be interpreted as residualized vocabulary gains. Results indicated that there were no significant differences among the three experimental conditions, Conceptual, Didactic and Review. As children's vocabulary scores were a proportion of items correct, the unstandardized estimates indicate that children in the Didactic group on average had posttest scores

0.01 and 0.02 higher than children in the Conceptual and Review conditions. Similar null effects were found for tests of condition differences for the study's Exposure words and Control words, ps $>0.151$. Estimates of experimental condition mean difference effect sizes in standard deviation units are provided in Table 1.

\subsection{Level of instruction}

Experimental conditions were equally effective, but we did not test if children learned the instructed words from instruction and through exposure. On average, children knew significantly more Instructed $(\beta=0.07, S E=0.01, p<0.001)$, Exposure $(\beta=0.06$, $S E=0.01, p<0.001)$ and $\operatorname{Control}(\beta=0.03, S E=0.01, p=0.044)$ words at posttest than at pretest (see Table 2 for estimates of effect sizes). To examine learning of words a within-subjects design (level of instruction repeated within children) was utilized as represented by the following model:

$$
\begin{aligned}
& \text { Posttest }_{\mathrm{ijk}}=\gamma_{000}+\gamma_{100} * \text { Exposure }_{\mathrm{ijk}}+\gamma_{200} * \text { Control }_{\mathrm{ijk}} \\
& +\gamma_{300} * \text { Pretest }_{\mathrm{ijk}}+\gamma_{001} * \text { Theme }_{\mathrm{k}}+\mathrm{U}_{00 \mathrm{k}}+\mathrm{U}_{0 \mathrm{jk}}+\mathrm{r}_{\mathrm{ijk}}
\end{aligned}
$$


The model accounted for three nesting levels in the data; level of instruction ${ }_{\mathrm{ijk}}$ (Instructed, Exposure, Control) was repeated within children. Children ${ }_{\mathrm{jk}}$ were nested within reading groups $\mathrm{s}_{\mathrm{k}}$. Level of instruction was dummy coded with Instructed words as the reference group which were contrasted with $\operatorname{Exposure}\left(\gamma_{100}\right)$ and Control $\left(\gamma_{200}\right)$ words. To look at residualized gains, children's pretest vocabulary scores $\left(\gamma_{300}\right)$ were included as a covariate along with book theme $\left(\gamma_{001}\right)$.

Across experimental conditions, children knew more Instructed words at posttest than Exposure and Control words, $\gamma_{100}=0.06$, $S E=0.01, p<0.001$ and $\gamma_{100}=0.08, S E=0.01, p<0.001$, respectively (Table 2). On average children were correct on $60.7 \%$ of the Instructed vocabulary items, $54.6 \%$ of the Exposure items, and $53.2 \%$ of the Control items. Post-hoc pairwise comparisons with LSD adjustments found that Exposure and Control word gains did not differ $(p=0.252)$.

Post-hoc exploratory analyses of level of instruction effects by experimental condition indicated that children demonstrated more receptive knowledge of Instructed words than Control words $(p<0.001)$ across the three conditions, $d=0.40,0.50$, and 0.39 for Didactic, Conceptual, and Review, respectively. Instructed words demonstrated significantly greater pre- to posttest gains than Exposure words $(p<0.001)$ across the three conditions, $d=0.53$, 0.32 , and 0.42 for Didactic, Conceptual, and Review, respectively.

\subsection{Initial vocabulary knowledge}

Finally, we considered whether the type of instruction provided for a word (Instructed, Exposure, Control) was moderated by children's initial vocabulary knowledge. We used the within-subjects model used in Eq. (2), with the addition of level-1 interactions: (1) the interaction between pretest scores and the dummy coded comparison of Instructed versus Control words $\left(\gamma_{400}\right)$ and $(2)$ the interaction between pretest scores and the dummy coded comparison of Exposure versus Control words $\left(\gamma_{500}\right)$. All model predictors were grand mean centered. Pretest vocabulary scores did not moderate the differential vocabulary gains for Exposure and Control words $(p=0.760)$, but it did moderate differential gains between Instructed and Control words, $\gamma_{300}=0.29, S E=0.09, p=0.011$.

Deconstruction of the interactions was conducted by estimating the region of significance for tests of simple slopes (Preacher, Curran, and Bauer, 2006). As indicated in Fig. 1, children who began the study with a pretest score greater than $39 \%$ percent correct $(0.75$ SD below the mean), made significantly greater gains on Instructed words than on Control words $(p<0.05)$. Children with pretest scores less than $39 \%$ made no gains. Those who began the study with a pretest score greater than $44 \%$ percent correct ( 0.46 SD below the mean) learned Instructed words better than Exposure words $(p<0.05)$; those with lower pretest scores showed no such benefit from explicit instruction.

\section{Discussion of Study 1}

We sought to determine the extent to which children learned words taught during book reading when provided varying amounts of information about word meanings, while also examining effects of word class and prior knowledge on learning. Instruction that used intentional instruction resulted in better pre-post learning than was seen for Control and Exposure words on the receptive test. Surprisingly, the two types of instruction that used explicit definitions, Conceptual and Didactic, resulted in learning gains that were not significantly greater than those seen for the Review condition that used an implicit instructional approach. While there was significant pre-post growth in knowledge of Exposure words, that improvement was not greater that what we found for Control words.

Prior studies compared explicit teaching to simple exposure (Coyne et al., 2007; Coyne et al., 2009; Sénéchal \& Thomas, 1995; Sénéchal, 1997) whereas we compared instructed words both to untaught control words and exposure words. Our finding is consistent with prior studies (Biemiller \& Boote, 2006; Blewitt et al., 2009; Coyne et al., 2007; Coyne et al., 2009; Sénéchal, 1997). The gain of 0.43 SD is similar that of Biemiller and Boote (2006) and was achieved while teaching 16 words per book.

A novel finding was that the Review condition resulted in significant learning that was equivalent to what we found using methods that called children's attention to the words and used definitions. In the Review condition, unlike in the Didactic and Conceptual conditions, all comments were focused on restating and clarifying a story event. Improved understanding of story events may have fostered learning. Also, in the Review condition children heard words four times as the story was read and eight times in teacher comments. This is the inverse of what occurred for exposure words (eight times in the story, four times by the teacher). Hearing words used more often as part of teacher comments may have increased their salience and supplied meaning cues not available from the story itself. The finding of the potency of our Review condition indicates that not all word learning needs to include explicit definitions. Rather, children may acquire information they need to construct word meanings from hearing words as the story is read and during discussions that reinforce their understanding of the story events.

We failed to find evidence of pre-post test learning of Exposure words that was greater than Control words. This is different from what others have reported. Coyne et al. and Sénéchal presented words incidentally and found that word learning increased with additional exposure (Coyne et al., 2007; Coyne et al., 2009; Sénéchal \& Thomas, 1995; Sénéchal, 1997). However they compared differences in growth associated with varying numbers of exposures; they did not compare growth in exposure words compared to untaught control words.

Children whose knowledge of words at pre-test was more than 0.75 SD below our group mean vocabulary pre-test showed greater instructional benefits than those with limited prior knowledge. Thus, all except those with the weakest language were similar in their ability to form initial representations of word meanings. This pattern is consistent with prior studies that have found Matthew effects (Authors, under review; Loftus et al., 2010; Marulis \& Neuman, 2010; Roskos et al., 2008), but different from studies and have used additional activities to supplement book reading (Neuman et al., 2011) or that have reversed (Authors, 2016b) this effect. Consistent with prior work, concrete nouns were learned more easily than other word types (Gentner, 1982; Hirsh-Pasek \& Golinkoff, 2006; Imai et al., 2008).

\section{Study 2}

Study 1 offered evidence that children learn words when teachers simply supply additional information about story events while using words as well as from hearing explicit definitions. We could not determine the depth of learning because we only assessed receptive knowledge, a measure of vocabulary breadth. In Study 2 we also examined depth of learning. Among 4th grade students, a study that tested the ability to verbally define words showed that depth predicted reading comprehension beyond the association explained by measures of breadth (Ouellette, 2006). Proctor et al. (2012) found depth predicted reading comprehension for 2 nd4th grade students after controlling for decoding and vocabulary breadth. These results are supported by findings from the National Early Literacy Panel's meta-analysis (2009), which suggests that 


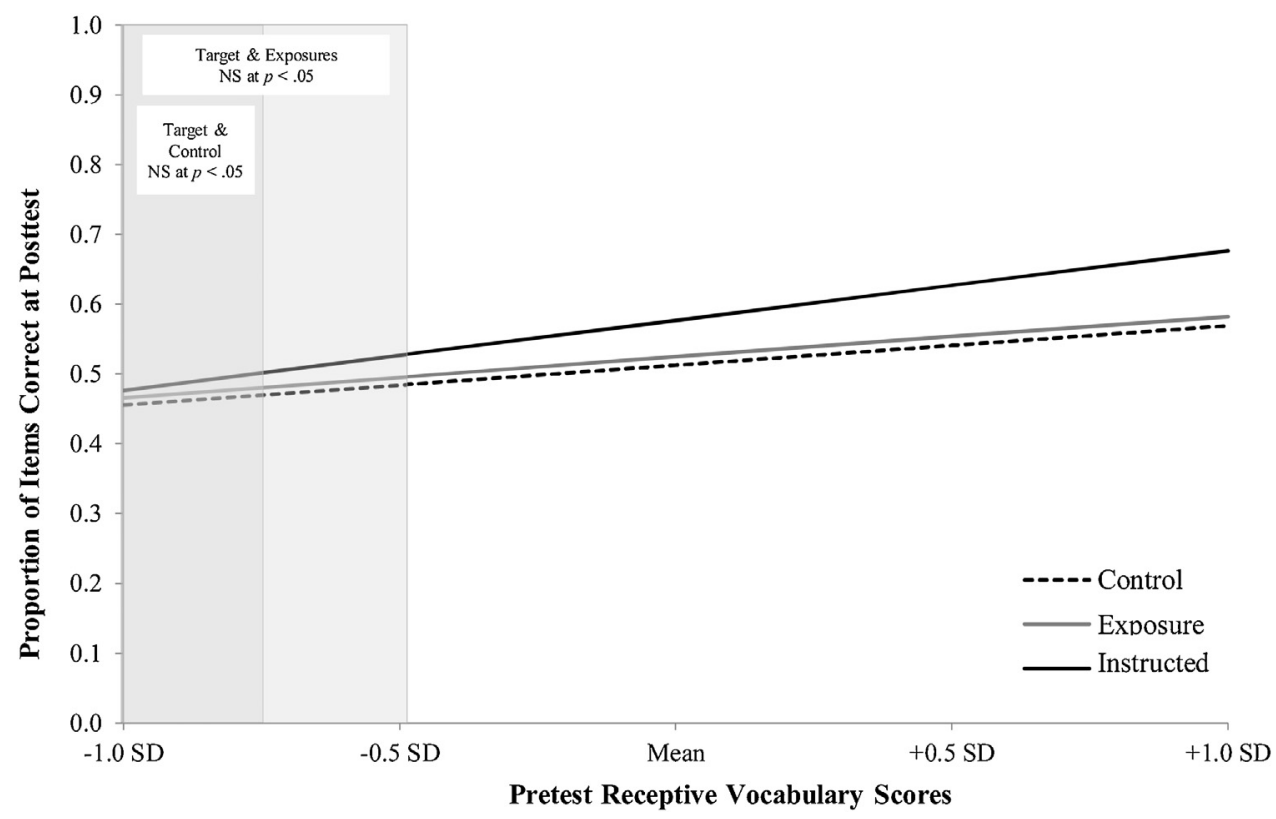

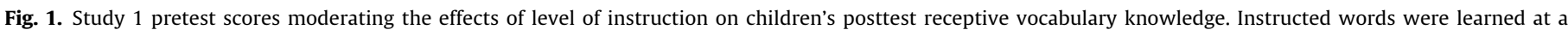

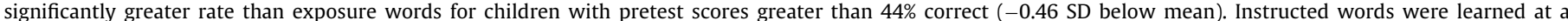
significantly greater rate than control words for children with pretest scores greater than $39 \%$ correct ( -0.75 SD below mean).

depth of knowledge is more predictive of later decoding and reading comprehension than breadth.

Given that our goal was to develop a single approach to book reading that would foster at least initial acquisition of many words and deep knowledge of selected words, we created a new composite reading method that combined elements of our three instructional methods and used both a receptive and expressive tools. To quickly foster deep learning teachers explicitly defined words, gave additional conceptual information, and helped explain story events by commenting on characters' goals and motivations and event sequences. We anticipated that all children would acquire initial knowledge of words but those with stronger vocabularies and richer associated knowledge networks would display more growth on our expressive measure. We were not satisfied with the effect size achieved with our intentional instruction in Study 1 and hypothesized that we had introduced too many novel words ( 16 instructed and 8 exposure); so we reduced the number of taught words to 10 . We also did not have the teachers use the exposure words as they talked about the story. Exposure to those words occurred only as the book was read. As in Study 1, children engaged in play with replicas related to the stories after the readings. We examined two research questions:

1. Do children make greater gains on both receptive and expressive knowledge when words are explicitly Instructed compared to Exposure words that are not highlighted? And are greater gains made on Exposure words compared to Control words that are never heard?

2. Is word learning for receptive and expressive knowledge moderated by initial vocabulary knowledge?

\subsection{Participants}

A subset of our total sample $(n=84)$ was randomly selected from children who participated in Study 1 . Children were $58 \%$ male and 58.64 months old ( $S D=5.48$ months). Fifty-five percent were African-American; 23\% were Hispanic/Latino; $15 \%$ were white; $1 \%$ were Asian; and $6 \%$ self-classified as "other." Seventeen percent were English Language Learners. Of the $26 \%$ of parents who reported that another language was spoken in the home $91 \%$ spoke Spanish. Seventy-nine percent of mothers reported school attainment: $15 \%$ had some high school; $45 \%$ had a high school diploma or GED; $23 \%$ attended trade school experience; $11 \%$ had an associate's degree; $5 \%$ had a BA degree; and $1 \%$ had graduate degrees.

\subsection{Procedures}

The experiment was conducted over a 2-month period, from the end of March to the middle of May. The same children tested in Study 1 participated in Study 2. Children were pre- and posttested by trained research assistants for knowledge of instructed, exposure, and control words within one week prior to and following the intervention and were randomly assigned to one of two books: half to the Farm theme (49\% of children) and others to the Dragon theme. Books were counterbalanced. Intervention Specialists (IS) read to mixed-gender groups of three children in a quiet location outside the classroom for four consecutive days. Book readings were video recorded. On average children were present for 3.52 $(S D=0.83)$ of book 1's four readings and $3.54(S D=0.85)$ of book 2's four readings.

\subsubsection{Book and word selection}

We used the same themes and books as Study 1 but no child received the same book. We used the same instructed words as in Study 1 unless a word had been correctly identified at pre-test by over $30 \%$. We replaced those using the same procedures to check on word difficulty as in Study 1.

\subsubsection{Book reading}

Children heard each Instructed word once as it was read in each of the four readings that took ten minutes. Eight explanations were given for each word, once during each reading, and once after each reading as part of a vocabulary and story plot review. The explanation used during the reading consisted of (1) drawing children's attention to a word by pointing to the picture that helped illustrate meaning (e.g., "look at the dragon's nose; these are his nostrils" [pointing to the nose in the picture]); (2) defining the word in childfriendly language; (3) iconic gestures when possible (e.g., galloping 
illustrated with moving fingers); and (4) an example of the word used in a context other than the one used in the story (e.g., we use nostrils to breathe air, not fire). On days 1 and 3 five Set A words received rich explanations similar to the Conceptual condition in Study 1 ; five Set B words were defined briefly. On days 2 and 4 Set B words were defined fully and Set A words were defined briefly. During the 3rd and 4th readings, children were asked to use the words to reinforce their phonological representations (e.g., "What do we call the little holes in our noses?") (see Appendix Table A1). Exposure words were only heard as the stories were read, including one use of the word in the text during each reading. Fidelity of implementation was checked from videotapes of IS delivery and found to be higher than $95 \%$ for all ISs.

\subsubsection{Play}

Ten-minute play sessions immediately followed each of the four book readings and included the same play prop kits as in Study 1.

\subsection{Measures}

\subsubsection{Receptive vocabulary}

This was assessed as in Study 1. The test for the dragon theme consisted of 34 items, while the farm theme tested 36 items. Each test was comprised of 20 Instructed words, 6-8 Exposure words, and 8 Control words.

\subsubsection{Expressive vocabulary}

To measure children's depth of knowledge we used a task that required children to express their knowledge of word meanings of instructed words. An experimenter-designed measure, adapted from Blewitt et al. (2009), was administered at pretest and posttest (Authors, 2016a). Children were asked to define concrete and abstract nouns, verbs, and adjectives verbally or using gesture. For each word, children were asked, "What is (a) _____?" and "Can you show me or tell me anything more about _.-_.?" Responses were transcribed and coded for information units (see Table A3). Responses were videotaped, transcribed, and coded for the amount of semantic information and examples of the target words use in the context given. Coding was conducted by research assistants, and $20 \%$ of all forms were randomly selected and checked for reliability against a lead coder after every four forms were completed. Overall percentage agreement averaged 93.2\%, with a mean Cohen's Kappa value of 0.82 .

The following categories were used for all word types. Synonyms included any word or short phrase that was equivalent to the word in question. Antonyms included responses that contained the opposite of the word being explained and "not" or another negating word. Gestures included actions or facial expressions that exemplified word meaning. We also coded for two uses of context. Extended context included responses that showed knowledge of the instructed word in a typical, meaningful context, along with semantic information. For example, if a child said, "A shovel is used to dig up weeds in a garden," "used to dig" would be scored for function, and "up weeds in a garden" would be scored for extended context, because the child has used a typical example to explain how a shovel could be used, along with the semantic information about function. Basic context, worth only $1 / 2$ a point, was a simple association between an instructed word and a typical context, without any inclusion of semantic information. For example, children frequently said "Santa Claus" for chimney, a response that does not include any semantic information but contains an association with a typical context in which the target word is used.

Four categories were used for concrete nouns only. Perceptual information included properties such as how something looks, smells, tastes, feels, or sounds. Functional information included any process, purpose, or use and answered the question, "What do you do with it?" Superordinate/subordinate included naming a larger category of which the word was a member or naming an exemplar member. Part/whole described a distinct part of the object represented by the noun or the whole of which the word was a part.

The test for the dragon theme consisted of 21 items, including 13 Instructed words, 4 Exposure words, and 4 Control words. The farm theme tested 18 items, including 8 Instructed words, 6 Exposure words, and 4 Control words (Table A3).

\section{Results}

\subsection{Descriptive statistics and baseline equivalence}

Pretest and posttest descriptives for the analytic sample by whether words were instructed, exposure, or control are provided in Table 2. To test for baseline equivalence multilevel regression models were conducted to estimate the association between pretest vocabulary and level of instruction. At pretest, children's receptive scores for the instructed words were lower than their scores for exposure, $\gamma=-0.09, S E=0.03, p<0.001$, and control words $\gamma=-0.09, S E=0.03, p<0.001$, which did not differ from each other (post-hoc LSD adjusted contrast, $p=953$ ). On the expressive measure, children's pretest scores for exposure words were higher than control words $\gamma=-0.15, S E=0.03, p<0.001$, and taught words, $\gamma=-0.22$, $S E=0.03, p<0.001$. Post-hoc LSD adjusted contrasts also found that control words had higher pretest scores than instructed words $(p=0.015)$. All subsequent analyses control for baseline vocabulary scores.

\subsection{Level of instruction}

On average, children knew more Instructed $\left(\beta_{\text {receptive }}=0.17\right.$, $\left.S E=0.02, p<0.001 ; \beta_{\text {expressive }}=0.42, S E=0.04, p<0.001\right)$ and Exposure $\left(\beta_{\text {receptive }}=0.07, S E=0.03, p=0.006 ; \beta_{\text {expressive }}=0.04, S E=0.02\right.$, $p=0.092$ ) words at posttest than at pretest (Table 2). Pre-posttest differences for Control words were not significant. To test for differential gains by level of instruction, we tested a model identical to Equation (2) from Study 1 with the addition of days of attendance $\left(\gamma_{020}\right)$ as a child-level independent variable. Student attendance information was collected in Study 2 to account for potential dosage effects as a result of absences (Range $=3-8$ days, $M=7.07, S D=1.35$ ).

As seen in Table 2, Instructed words were learned more readily than Control words, with covariate adjusted posttest scores of $62.0 \%$ and $53.2 \%$ correct, respectively. There was a trend $(p=0.063)$ for Exposure words (adjusted posttest of 57.4\%) to be learned better than Control words. Post hoc pairwise comparisons indicate that there was a trend $(p=0.072)$ for Instructed words to be learned better than Exposure words. Estimates of level of instruction mean difference effect sizes are provided in Table A3.

Children made significantly larger expressive gains for both Instructed and Exposure words compared to Control words (Table 3). On average on the posttest, after controlling for model covariates, children scored 0.70 points per word for the Instructed vocabulary items, 0.43 points for the Exposure items, and 0.30 points for the Control items. Post hoc pairwise comparisons confirm that Instructed words were learned better than Exposure words $(p<0.001)$. Estimates of mean difference effect sizes are provided in Table 4.

\subsection{Initial vocabulary knowledge}

Lastly, we tested to see whether the differential effects of level of instruction were moderated by children's initial vocabulary knowledge using the same approach as Study 1 . For the receptive vocabulary, main effects of larger Instructed word gains 
Table 3

Study 2 fixed effect parameter estimates (Standard Errors) and effect sizes for models estimating differences in level of instruction for receptive and expressive vocabulary gains at posttest (Control = Reference Group).

\begin{tabular}{lll}
\hline & Receptive vocabulary & Expressive knowledge \\
\hline Level 1, level of instruction & & \\
$\quad$ Intercept, $\gamma_{000}$ & $0.263(0.094)$ & $0.275(0.129)$ \\
$\quad$ Instructed versus Control, $\gamma_{100}$ & $0.088(0.023)^{* * *}$ & $0.394(0.048)^{* *}$ \\
$\quad \begin{array}{l}\text { Exposure versus Control, } \gamma_{200} \\
\quad \text { Pretest performance, } \gamma_{300}\end{array}$ & $0.041(0.023)^{+}$ & $0.129(0.049)^{*}$ \\
$\begin{array}{l}\text { Level 2, child } \\
\quad \text { Attendance, } \gamma_{020}\end{array}$ & $0.015(0.012)^{*}$ & $0.508(0.075)^{* *}$ \\
$\quad$ Level 3, play group & & $0.001(0.023)$ \\
$\quad$ Theme $\left(0=\right.$ Farm), $\gamma_{001}$ & $-0.010(0.032)^{* *}$ & $-0.089(0.060)$ \\
\hline
\end{tabular}

Note: standard errors adjusted for interdependency among observations. Level of instruction (Level 1) was repeated within children (Level 2) who were nested within Play Groups (Level 3). Exposure instruction is the reference group $\left(\gamma_{100}, \gamma_{200}\right)$ for the comparison of instruction differences; as such, positive estimates indicate that children made greater gains in the non-reference group (taught or no instruction). Negative estimates for Theme $\left(\gamma_{001}\right)$ indicate that children in the Dragon theme had smaller posttest scores compared to children in the Farm theme.

${ }^{*} p<0.05$.

$p<0.01$.

${ }^{t} p<0.10$.

compared to Exposure and Control words were not moderated by initial vocabulary knowledge, $\gamma_{400}=0.21, S E=0.18, p=0.254$ and $\gamma_{500}=-0.23, S E=0.18, p=0.192$, respectively. However, for children who entered the study with more receptive knowledge, positive gains in Exposure words, compared to Control words, were more pronounced, $\gamma=0.43, S E=0.15, p=0.005$.

For the expressive task pretest vocabulary moderated the differential vocabulary gains between Instructed and Control words, $\gamma_{300}=0.54, S E=0.22, p=0.017$. Post hoc comparisons also found that pretest vocabulary scores moderated the differential vocabulary gains made for Instructed words and Exposure words, $\gamma=0.58$, $S E=0.18, p=0.001$. Explorations of the multilevel interactions (Fig. 2) indicated that greater gains of Instructed words, compared to both Exposure and Control words, were most pronounced for children who entered the study with more expressive knowledge. Yet, differences in gains for Exposure and Control words' expressive knowledge were not moderated by initial vocabulary, $\gamma_{500}=0.03$, $S E=0.18, p=0.864$.

\subsection{Discussion of Study 2}

Study 2 addressed two new questions. First, we tested for learning effects using both a receptive and expressive task in order to probe for depth of learning effects. Second, we tested the effectiveness of a new composite book reading method for teaching vocabulary controlling for word type and prior knowledge of the words.

When we compared all directly instructed words with control words, we found moderate effects on the receptive task $(d=0.48)$ but large effects $(d=1.19)$ on the expressive task. Also, for exposure words, children showed statistically significant growth in receptive knowledge compared with control words $(d=0.22)$ and on the expressive task there was a moderate sized effect for exposure compared to instructed words $(d=0.63)$. There was growth in knowledge of words that children simply heard as the books were read, with this being found with the expressive task. Prior knowledge of words did not moderate learning of taught words when measured by our receptive tool, suggesting that children with varying prior knowledge of language formed initial representations at a similar rate. Prior knowledge did affect growth of expressive knowledge of instructed words, suggesting that children with more well developed vocabularies and associated knowledge were able to associated new words with existing networks more quickly. Stronger initial vocabulary also enabled children to more quickly form the initial representations described by our receptive measure. Evidence of growth from exposure to words reinforces the finding from Study 1 that children can make gains in word learning when they hear novel words multiple times in meaningful contexts of explicit instruction.

\section{General discussion}

We explored the mechanisms of word learning by preschoolaged children in full group book reading while we were devising an approach that preschool teachers can use to build the breadth and depth of children's vocabulary. We hypothesized that children with varying levels of knowledge of English vocabulary can form initial representations of words when taught in group book reading using methods that repeatedly present words in meaningful contexts in text and teacher comments. Results of Study 1 supported that finding. Children made equivalent growth in receptive knowledge across our three methods. Results of Study 2 also showed, when they are directly taught words, all children acquire initial knowledge of words as measured by our receptive measure at a similar rate. We also hypothesized that children with stronger initial vocabulary would acquire words more quickly, and these gains would be most evident in their ability to learn words from simple exposure. We found that to be true, and also discovered that they more quickly formed deeper representations as measured by our expressive tool.

Table 4

Examples of expressive coding of different word types.

\begin{tabular}{|c|c|c|c|}
\hline Word type & Instructed word & Sample response & Code \\
\hline \multirow[t]{4}{*}{ Concrete noun } & Basket & “You carry stuff with it.' & Function \\
\hline & Chimney & "Made of bricks." & Part/whole \\
\hline & Shield & $\begin{array}{l}\text { "[A] shield protects you when you get in a fight } \\
\text { with a dragon and he blows fire at you." }\end{array}$ & Function, meaningful context \\
\hline & Throne & "A throne is golden." & Perceptual quality \\
\hline Abstract noun & Foolishness & "Foolishness means that you're acting crazy." & Synonym \\
\hline \multirow[t]{5}{*}{ Verb } & Chuckling & "A quiet laugh." & Synonym \\
\hline & Fetching & $\begin{array}{l}\text { "I throw the ball to my dog and he fetches it } \\
\text { and gives it to me." }\end{array}$ & Meaningful context \\
\hline & Returning & "Run away and go back. In the story the farmer & Synonym \\
\hline & & ran away and he never came back." & Meaningful context \\
\hline & Sobbing & "You crying." & Synonym \\
\hline Adjective & Intelligent & $\begin{array}{l}\text { "Means that you could build a science fair } \\
\text { project." }\end{array}$ & Basic context \\
\hline
\end{tabular}




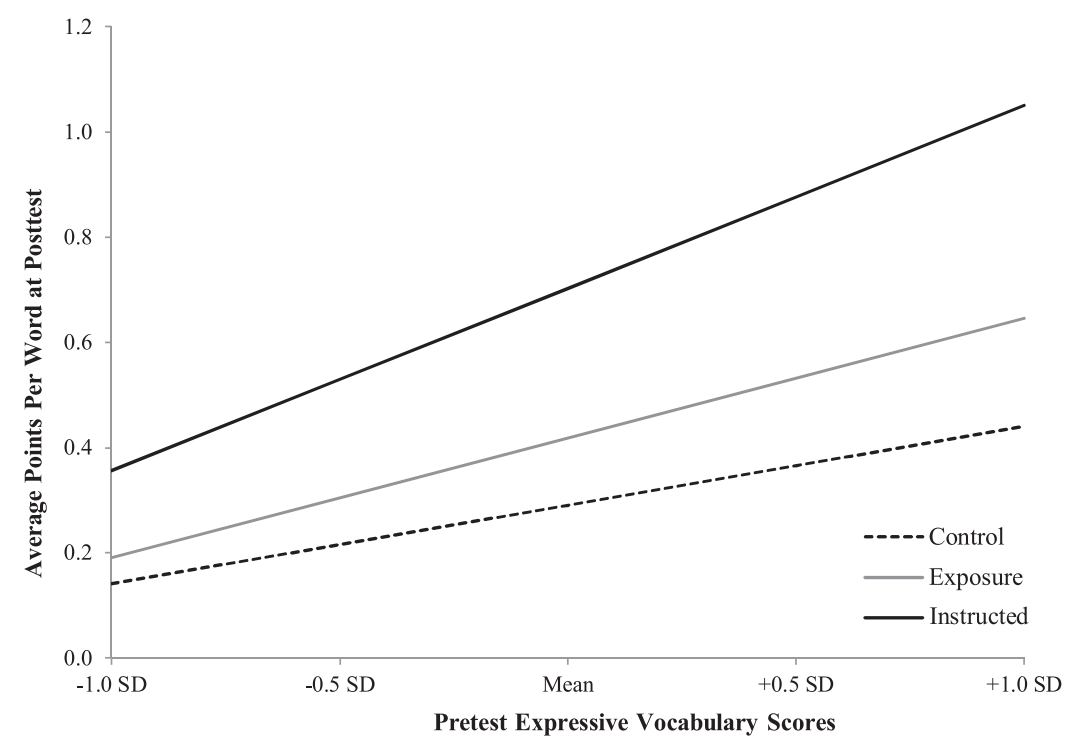

Fig. 2. Study 2 pretest scores moderating the effects of level of instruction on children's posttest expressive vocabulary knowledge.

\subsection{Prior research}

\subsubsection{Explicit instruction}

We devised our intervention to include practices that could quickly establish connections between existing knowledge by using explicit definitions, referencing pictures, and connecting words to events being depicted in the books. Such connections should help children begin to establish deep knowledge of words. Recognizing that word type and prior knowledge of vocabulary affect word learning we took these factors into consideration in our instructional design. We hoped that such instruction would minimize Matthew Effects.

In Study 1 we tested the effects of supplying different sources of information about word meanings: formal definitions, supplementary conceptual information, picture references, gestures and connection to story events. In both Experiments 1 and 2 our explicit instructional methods resulted in similar growth of receptive knowledge when comparing pre-post growth of taught compared to control words: Study 1: $d=0.43$; Study 2: $d=0.48$. This is essentially the same as the average 0.45 effect size found by Mol et al. (2009) in their meta-analysis of 31 book reading studies and the fixed effect of 0.47 found by the National Early Literacy Panel (2009) when it excluded an outlier. The absence of Matthew Effects indicated that all children were able to form the type of initial representations tapped by our receptive measure.

In Study 2 we also examined the effects of our Composite explicit method using an expressive measure designed to tap depth of knowledge and found an effect of $d=1.19$. This effect is $45 \%$ stronger than the average effect of $d=0.66$ on expressive measures found by Mol et al. (2009) and twice the size of expressive gains found by Neuman and Dwyer (2011) ( $d=0.64)$, who used book reading, supplementary activities and videos. We achieved these outcomes while teaching 10 words. It is comparable to the 12 and 10 words taught, respectively, by Biemiller and Boote (2006) and Lever and Sénéchal (2011) and more words than the four and six, respectively, taught by Tuckwiller, Pullen, and Coyne (2010) and Coyne et al. (2007, 2009). Our expressive gains also are stronger than the effects found by Beck and McKeown (2007) for pre-post growth in productive knowledge $(d=0.70)$ of 10 words taught over four readings with follow up discussion. They provided 12 encounters with each word.

Our findings speak to the importance of probing for depth of vocabulary knowledge as it reveals more clearly what children know about the vocabulary they learn. Depth is also significantly associated with reading comprehension (Ouellette, 2006; Proctor et al., 2012). Comprehension is enhanced when readers have deep, flexible word knowledge that affords quick lexical access and activation of networks of associated knowledge (Beck \& McKeown, 2007; Silverman \& Hartranft, 2015; Stahl \& Fairbanks, 1986; Perfetti \& Stafura, 2014).

\subsection{Learning from implicit instruction and exposure}

There is a pressing need to find the right balance between rich instruction that builds deep knowledge of a few words and less intensive teaching that helps children begin to acquire many new words. A particularly surprising result was the finding from our Review condition, which was used to mimic the kind of comments an effective teacher might make while explaining story events to children. Instructed words were used but the teacher did not call direct attention to the words nor did she give children definitions for words. Statistical analyses of our receptive data revealed that the three instructional methods in Study 1 were helpful, but effect size comparisons showed that the Review condition effects were somewhat smaller (Didactic: $d=0.15$; Conceptual: $d=0.10$ ). Teacher comments about stories have been found to result in vocabulary learning (Barnes \& Dickinson, 2017; Barnes et al., 2017). This finding provides experimentally controlled insight into one way such comments may support learning. Our result is also consistent with research done with third graders that found enhanced learning of verbs when words were used in sentences in which the novel verb activated knowledge of a familiar script (e.g., birthday party) that was relevant to the word. They were learned better than words that lacked linkage to event knowledge (Chilton \& Ehri, 2015). Our finding is consistent with Chilton and Ehri's result and suggests that event knowledge helps enrich lexical representations.

We also found evidence that word learning may occur as children repeatedly hear words as books are read and discussed. When we examined pre-post growth of exposure words we found trends suggesting more growth for exposure than control words for receptive (Study1, $d=0.08$; Study $2, d=0.22$ ) and expressive knowledge (Study 2, d=0.37). The finding of improvement in knowledge of exposure words on the expressive measure in Study 2 was surprising. We had anticipated that, if exposure gains were found, they would show up on the receptive measure because it would be a more sensitive means of detecting less fully developed lex- 
ical entries. The finding of gains on the expressive task suggests that simply hearing words using in meaningful contexts can enable preschool-aged children to link words to existing knowledge networks.

It is surprising that there was more evidence of gains in knowledge resulting from simple exposure in Study 2 than in Study 1. In Study 2 children only heard words four times as the story was read compared with 12 times in Study 1 . There are two possible reasons for this result. First, the children participated in both experiments and may have become more attuned to words and skilled at creating initial word representations during book reading. Second, in Study 2, the Composite method was similar to the Conceptual condition of Study 1 . While there were no statistically significant differences across conditions in pre-post growth in Study 1, the effect size for the Conceptual condition was nearly twice as large as was found for Didactic and Review (Conceptual: $d=0.52$, Didactic: $d=0.23$; Review: $d=0.30$ ). Hearing elaborated information about word meanings in the Conceptual condition in Study 1 and in Study 2 may have encouraged children to more actively engage in efforts to understand novel words they heard while listening to the story.

Our results suggest that we can build the breadth of children's word knowledge through methods that do not require much instructional time as long as teachers supply cues to word meanings by referencing pictures, making comments that use the words while explaining story events, and rereading books in a way that holds children's interest. Such exposure mirrors interactions that support language learning in homes (Hoff, 2006; Weizman \& Snow, 2001).

\subsection{Matthew Effects}

In both studies, prior word knowledge significantly moderated post-test gains in knowledge of words compared to control words. Note that seventeen percent of the children were classified as "English Language Learners." We did not find that designation to affect our results; therefore, we used the continuous variable of prior word knowledge. Presumably, many of the children with weaker prior knowledge also were learning English as a new language.

We were interested in determining if our explicit instructional methods could provide reasonably equal support for word learning to children with varying levels of vocabulary knowledge. We reasoned that targeting explicit instruction on a relatively small number of words might provide the opportunity for children of varying language ability to make roughly similar learning gains. Study 1 results for our receptive task failed to support that hypothesis, but the cut point at which gains varied was 0.75 SD below the mean of our sample. Thus, learning gains of most children were not affected by prior word knowledge. Thus, prior knowledge conditions both how quickly children acquire a broad and deep vocabulary, but intentional instruction can help to equalize learning gains.

Study 2 yielded a somewhat different pattern of results when we compared instructed with control words. No Matthew effect was found for the receptive task, but an effect was found on the expressive task. We interpret this finding as suggesting that children with weaker language skills were acquiring initial representations of words at a rate roughly comparable to more advanced language learners, but that children with a greater fund of pre-existing knowledge of words and the world were more able to quickly construct deeper representations that were tapped by our expressive task. We also found that children with stronger prior word knowledge were more likely to form initial representations of words taught through exposure. This ability to acquire words through context draws on syntactic skill, speed of lexical processing, and lexical and semantic networks that provide points of contact for new words.

Our Matthew effect results are in line with Marulis and Neuman's (2010) review of 67 vocabulary interventions that found Matthew Effects repeatedly (Authors, under review; Coyne et al., 2007, 2009; Loftus et al., 2010; Roskos et al., 2008). These effects are reversed when word learning is fostered while playing a game (Authors, 2016b), suggesting that our future efforts to combine reading with play may enable those with weaker initial knowledge to show even more growth.

\subsection{Conclusion}

We conclude that when provided intentional instruction, children of varying language abilities construct initial representations of word meanings and their ability to do so is only weakly moderated by prior vocabulary knowledge. While it has long been recognized that explicit teaching that includes explicit definitions speeds word learning, we found that implicit instruction that included use of the words while enriching word-related knowledge also is an effective means of teaching words. Intentional instruction helps to mitigate Matthew Effects, especially when initial word learning is assessed using a receptive measure. In Study 1, effects of prior vocabulary were found only among the weakest language learners and were not present in Study 2. We further conclude that prior knowledge affects the speed with which children build the more elaborated networks of word knowledge revealed by our expressive task as indicated by the Matthew Effect found in Study 2. A final finding is that children can learn words from exposure, with this being most likely to occur among children with stronger language skills. Thus, book reading can be used to foster acquisition of broad vocabulary knowledge by supplying exposure to many words by reading texts and providing quick clues to their meanings (e.g., pointing to pictures, using gestures or prosodic clues). Depth can be fostered for a subset of the words a child experiences during a book reading through intentional instruction that builds knowledge associated with words and supplies word definitions. Prior knowledge also affects how fast deep representations are constructed. To counteract Matthew Effects on development of deeper knowledge of word meanings classrooms need to provide supplementary experiences that augment the relatively thin semantic information that can be gained during book reading. Thematically related units that include enrichment such as science activities, games and music that use words all may help provide the concepts and experiences needed to create strong lexical representations.

\subsection{Limitations and future directions}

One limitation of our studies is that the same children were in both experiments, despite the fact that children did not get the same theme and books across experiments. It is feasible that being exposed to storybook reading approaches in Study 1 could have affected performance in Study 2. However, the pretest scores for Study 2 were either comparable to or less than those found in Study 1. Also, the absence of an expressive measure for Study 1 makes it impossible to fully examine the impact of the different types of instruction we provided. Finally, the approaches used were highly scripted. Teachers would not be likely to remain so tightly bound to our methods so it remains to be determined whether the effects we found can be replicated in a teacher-delivered study.

Another limitation is the fact that in both experiments after the book reading children were given $10 \mathrm{~min}$ for free play using the props. This was done for methodological reasons associated with our larger program of research and a follow-up study that used the same methods found no evidence that the free play method we employed resulted in word learning (Toub et al., 2018) 
Finally, in these studies the methods were used by trained research assistants working with groups of three children. We could not be sure that effects obtained under these ideal circumstances could be replicated by teachers as they read to full groups of children. However, subsequent studies in which we used essentially the same methods did yield effects that are equal to or stronger than what we obtained here (Authors, 2016a, 2016b, 2018).

\subsection{Implications}

While there is clearly a need to improve the vocabulary knowledge of children with the weakest abilities, we also need to enrich the knowledge of children who enter classrooms with stronger lan- guage. Children with stronger language have been found to benefit especially from instructional contexts that are language-rich but not heavily instructionally focused (Conner, Morrison, \& Slominski, 2006). Our results suggest that all children benefit from explicit and implicit intentional instruction during book reading as well as from hearing words in context. The fact that more able children benefit more from such experiences is not problematic; rather it means that, as teachers provide direct instruction about selected words, they also need to enrich children's knowledge of many other words by using interesting and varied words as they discuss stories.

\section{Appendix}

Table A1

Intervention design: exposure and instructed instructional study day.

\begin{tabular}{|c|c|c|c|c|}
\hline & Day one & Day two & Day three & Day four \\
\hline \multicolumn{5}{|l|}{ Study 1} \\
\hline Exposure & Sets $A$ and $B$ & Sets $A$ and $B$ & Sets A and B & Sets $A$ and $B$ \\
\hline$n=8$ reading & Read 2x & Read 2x & Read 2x & Read 2x \\
\hline \multirow[t]{2}{*}{$n=4$ teacher use } & Set $A$ & Set B & Set A & Set B \\
\hline & Teacher use $^{1} 2 \mathrm{x}$ & Teacher use $2 \mathrm{x}$ & Teacher use $2 \mathrm{x}$ & Teacher use $2 \mathrm{x}$ \\
\hline Instructed & Sets A and B: & Sets $A$ and $B$ : & Sets A and B: & Sets $A$ and $B$ : \\
\hline$n=4$ reading & Read 1x & Read 1x & Read 1x & Read 1x \\
\hline \multirow[t]{3}{*}{$n=8$ teacher use } & Set A: & Set B: & Set A: & Set B: \\
\hline & Taught $^{2} 2 \mathrm{x}$ during story & Taught $2 \mathrm{x}$ during story & Taught $^{2} 2 \mathrm{x}$ during story & Taught $2 \mathrm{x}$ during story \\
\hline & Taught $2 \mathrm{x}$ after story & Taught $2 \mathrm{x}$ after story & Taught $2 \mathrm{x}$ after story & Taught $2 \mathrm{x}$ after story \\
\hline \multicolumn{5}{|l|}{ Study 2} \\
\hline $\begin{array}{l}\text { Exposure } \\
n=4 \text { reading }\end{array}$ & Read 1x & Read $1 \mathrm{x}$ & Read 1x & Read 1x \\
\hline Instructed & Read 1x & Read 1x & Read 1x & Read 1x \\
\hline$n=4$ reading & Taught $1 \mathrm{x}$ during story & Taught $1 \mathrm{x}$ during story & Taught $1 \mathrm{x}$ during story & Taught $1 \mathrm{x}$ during story \\
\hline$n=4$ teacher use & Taught $1 \mathrm{x}$ after story & Taught $1 \mathrm{x}$ after story & Taught $1 \mathrm{x}$ after story & Taught $1 \mathrm{x}$ after story \\
\hline
\end{tabular}

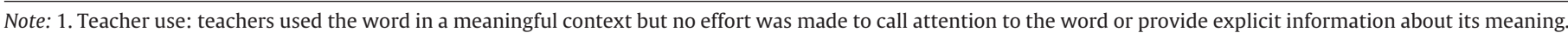
2. Words were taught in ways described above for the different experimental conditions.

Table A2

Examples of taught and exposure words by form class.

\begin{tabular}{|c|c|c|}
\hline Form class & Taught word & Exposure word \\
\hline Concrete noun & $\begin{array}{l}\text { Nostrils } \\
\text { Handkerchief } \\
\text { Shield }\end{array}$ & $\begin{array}{l}\text { Cave } \\
\text { Incisors } \\
\text { Talons }\end{array}$ \\
\hline Abstract noun & $\begin{array}{l}\text { Quarrel } \\
\text { Sorrow } \\
\text { Meeting }\end{array}$ & Reflection \\
\hline Verb & $\begin{array}{l}\text { Charging } \\
\text { Fetching } \\
\text { Sobbing }\end{array}$ & $\begin{array}{l}\text { Exhaled } \\
\text { Waddled }\end{array}$ \\
\hline Adjective & $\begin{array}{l}\text { Intelligent } \\
\text { Peaceful }\end{array}$ & Speechless \\
\hline Spatial preposition & $\begin{array}{l}\text { Onto } \\
\text { Below }\end{array}$ & Behind \\
\hline
\end{tabular}




\section{References}

Anderson, R. C., \& Freebody, P. (1981). Vocabulary knowledge. In T. Guthrie (Ed.), Comprehension and teaching: Research reviews (pp. 77-117). Newark, DE: International Reading Association.

Authors. (2016a).

Authors. (2016b).

Authors. (under review).

Barnes, E. M., \& Dickinson, D. K. (2017). The impact of teachers' commenting strategies on children's vocabulary growth. Exceptionality, 25(3), 186-206. http://dx.doi.org/10.1080/09362835.2016.1196447

Barnes, E. M., Dickinson, D. K., \& Grifenhagen, J. F. (2017). The role of teachers' comments during book reading in children's vocabulary growth. Journal of Educational Research, 110(5), 515-527. http://dx.doi.org/10.1080/00220671. 2015.1134422

Beck, I. L., \& McKeown, M. G. (2007). Increasing young low-income children's oral vocabulary repertoires through rich and focused instruction. Elementary School Journal, 107(3), 251-271. http://dx.doi.org/10.1086/511706

Biemiller, A., \& Boote, C. (2006). An effective method for building meaning vocabulary in primary grades. Journal of Educational Psychology, 98(1), 44-62. http://dx.doi.org/10.1037/0022-0663.98.1.44

Biemiller, A. (2010). Words worth teaching: Close the vocabulary gap. Columbus, $\mathrm{OH}$ : McGraw Hill.

Blewitt, P., Rump, K. M., Shealy, S. E., \& Cook, S. A. (2009). Shared book reading: When and how questions affect young children's word learning. Journal of Educational Psychology, 101(2), 294-304. http://dx.doi.org/10.1037/a0013844

Brabham, E. G., \& Lynch-Brown, C. (2002). Effects of teachers' reading-aloud styles on vocabulary acquisition and comprehension of students in the early elementary grades. Journal of Educational Psychology, 94(3), 465-473. http://dx. doi.org/10.1037//0022-0663.94.3.465

Cain, K., \& Oakhill, J. (2011). Matthew Effects in young readers: Reading comprehension and reading experience aid vocabulary development. Journal of Learning Disabilities, 44(5), 431-443. http://dx.doi.org/10.1177/ 0022219411410042

Carey, S. (1978). The child as word learner. In M. Halle, J. Bresnan, \& A. Miller (Eds.) Linguistic theory and psychological reality (pp. 264-293). Cambridge, MA: MIT Press.

Carey, S. (2010). Beyond fast mapping. Language Learning and Development, 6(3), 184-205. http://dx.doi.org/10.1080/15475441.2010.484379

Chilton, M. W., \& Ehri, L. C. (2015). Vocabulary learning: Sentence contexts linked by events in scenarios facilitate third graders' memory for verb meanings. Reading Research Quarterly, 50(4), 439-458. http://dx.doi.org/10.1002/rrq.106

Collins, M. F. (2010). ELL preschoolers' English vocabulary acquisition from storybook reading. Early Childhood Research Quarterly, 25(1), 84-97.

Conner, C. M., Morrison, F. J., \& Slominski, L. (2006). Preschool instruction and children's emergent literacy growth. Journal of Educational Psychology, 98(4), 665-689.

Cooper, H. (1998). Pumpkin soup. Great Britian: Doubleday.

Coyne, M. D., Kame'enui, E. J., Simmons, D. C., \& Harn, B. A. (2004). Beginning reading intervention as inoculation or insulin: First-grade reading performance of strong responders to kindergarten intervention. Journal of Learning Disabilities, 37(2), 90-104. http://dx.doi.org/10.1177/00222194040370020101

Coyne, M. D., McCoach, D. B., \& Kapp, S. (2007). Vocabulary intervention for kindergarten students: Comparing extended instruction to embedded instruction and incidental exposure. Learning Disability Quarterly, 30(2), 74-88. http://dx.doi.org/10.2307/30035543

Coyne, M. D., McCoach, D. B., Loftus, S., Zipoli, R., \& Kapp, S. (2009). Direct vocabulary instruction in kindergarten: Teaching for breadth versus depth. Elementary School Journal, 110(1), 1-18. http://dx.doi.org/10.1086/598840

dePaola, T. (1980). The knight and the dragon. New York: G. P. Putnam's Sons.

Dickinson, D. K., \& Porche, M. V. (2011). Relation between language experiences in preschool classrooms and children's kindergarten and fourth-grade language and reading abilities. Child Development, 82(3), 870-886. http://dx.doi.org/10. 1111/j.1467-8624.2011.01576.x

Dickinson, D. K., \& Smith, M. W. (1994). Long-term effects of preschool teachers' book readings on low-income children's vocabulary and story comprehension. Reading Research Quarterly, 29(2), 105-122.

Dickinson, D. K., \& Tabors, P. O. (Eds.). (2001). Beginning literacy with language: Young children learning at home and school. Baltimore, MD: Brookes Publishing.

Dickinson, D. K., Hofer, K. G., Barnes, E. M., \& Grifenhagen, J. B. (2014). Examining teachers' language in head start classrooms from a systemic linguistics approach. Early Childhood Research Quarterly, 29, 231-244. http://dx.doi.org/ 10.1016/j.ecresq.2014.02.006

Dickinson, D. K., Collins, M. F., Nesbitt, K. T., Toub, T. S., Hassinger-Das, B., Hadlely, E. B., Hirsh-Paske, K., \& Golinkoff, R. M. (2018). Effects of teacher-delivered book reading and play on vocabulary learning and self-regulation among low-income preschool children. Journal of Cognition and Development, https:// doi.org/10.1080/15248372.2018.1483373

Dickinson, D. K. (1984). First impressions: Children's knowledge of words after a single exposure. Journal of Applied Psycholinguistics, 5, 359-373. http://dx.doi. org/10.1017/S0142716400005233

Dunn, L. M., \& Dunn, D. M. (2007). Peabody picture vocabulary test - 4. Minneapolis MN: Pearson.

Estes, K. G., Evans, J. L., Alibali, M. W., \& Saffran, J. R. (2007). Can infants map meaning to newly segmented words? Statistical segmentation and word learning. Psychological Science, 18(3), 254-260. http://dx.doi.org/10.1111/j. 1467-9280.2007.01885.x

Farkas, G., \& Beron, K. (2004). The detailed age trajectory of oral vocabulary knowledge: Differences by class and race. Social Science Research, 33(3) 464-497. http://dx.doi.org/10.1016/j.ssresearch.2003.08.001

Gentner, D. (1982). Why nouns are learned before verbs: Linguistic relativity versus natural partitioning. University of Illinois at Urbana-Champaign.

Gonzalez, J. E., \& Nelson, J. R. (2003). Stepping stones to literacy: A prevention-oriented phonological awareness training program. Reading and Writing Quarterly: Overcoming Learning Difficulties, 19(4), 393-398.

Gonzalez, J. E., Pollard-Durodola, S., Simmons, D. C., Taylor, A. B., Davis, M. J., Kim, M., \& Simmons, L. (2010). Developing low-income preschoolers' social studies and science vocabulary knowledge through content-focused shared book reading. Journal of Research on Educational Effectiveness, 4(1), 25-52. http://dx. doi.org/10.1080/19345747.2010.487927

Hadley, E. B., \& Dickinson, D. K. (2018). Measuring young children's word knowledge: A conceptual review. Journal of Early Childhood Literacy, http://dx. doi.org/10.1177/1468798417753713 [1468798417753713]

Hadley, E. B., et al. (2016). Examining the acquisition of vocabulary knowledge depth among preschool students. Reading Research Quarterly, 51(2), 181-198.

Hadley, E. B., Dickinson, D. K., Hirsh-Pasek, K., \& Golinkoff, R. M. (2018). Building semantic networks: The impact of a vocabulary intervention on preschoolers' depth of word knowledge. Reading Research Quarterly.

Hargrave, A. C., \& Senechal, M. (2000). A book reading intervention with preschool children who have limited vocabularies: The benefits of regular reading and dialogic reading. Early Childhood Research Quarterly, 15(1), 75-90. http://dx.doi. org/10.1016/S0885-2006(99)00038-1

Hindman, A. H., Erhart, A. C., \& Wasik, B. A. (2012). Reducing the Matthew Effect: Lessons from the excell head start intervention. Early Education and Development, 23(5), 781-806. http://dx.doi.org/10.1080/10409289.2010. 549443

Hirsh-Pasek, K., \& Golinkoff, R. M. (Eds.). (2006). Action meets word: How children learn verbs. New York, NY: Oxford University Press.

Hoff, E., \& Naigles, L. (2002). How children use input to acquire a lexicon. Child Development, 73(2), 418-433. http://dx.doi.org/10.1111/1467-8624.00415

Hoff, E. (2006). Environmental supports for language acquisition. In D. K. Dickinson, \& S. B. Neuman (Eds.), Handbook of early literacy research (Vol. II) (pp. 163-172). New York: Guilford.

Huttenlocher, J., Haight, W., Bryk, A., Seltzer, M., \& Lyons, T. (1991). Early vocabulary growth: Relation to language input and gender. Developmental Psychology, 27, 236-248

Imai, M., Li, L., Haryu, E., Hirsh-Pasek, K., Golinkoff, R. M., \& Shigematsu, J. (2008). Novel noun and verb learning in Chinese, English, and Japanese children: Universality and language-specificity in novel noun and verb learning. Child Development, 79, 979-1000.

Justice, L. M., Meier, J., \& Walpole, S. (2005). Learning new words from storybooks: An efficacy study with at-risk kindergartners. Language Speech and Hearing Services in Schools, 36(1), 17-32. http://dx.doi.org/10.1044/0161-1461(2005/ 003)

Lever, R., \& Sénéchal, M. (2011). Discussing stories: On how a dialogic reading intervention improves kindergartners' oral narrative construction. Journal of Experimental Child Psychology, 108(1), 1-24. http://dx.doi.org/10.1016/j.jecp. 2010.07 .002

Loftus, S. M., Coyne, M. D., McCoach, D. B., Zipoli, R., \& Pullen, P. C. (2010). Effects of a supplemental vocabulary intervention on the word knowledge of kindergarten students at risk for language and literacy difficulties. Learning Disabilities Research \& Practice, 25(3), 124-136. http://dx.doi.org/10.1111/j. 1540-5826.2010.00310.x

Ma, W., Golinkoff, R. M., Hirsh-Pasek, K., McDonough, C., \& Tardif, T. (2009). Imageability predicts the age of acquisition of verbs in Chinese children. Journal of Child Language, 36, 405-423.

Mancilla-Martinez, J., \& Lesaux, N. K. (2011). Early home language use and later vocabulary development. Journal of Educational Psychology, 103(3), 535-546. http://dx.doi.org/10.1037/a0023655

Marulis, L. M., \& Neuman, S. B. (2010). The effects of vocabulary intervention on young children's word learning: A meta-analysis. Review of Educational Research, 80(3), 300-335. http://dx.doi.org/10.3102/0034654310377087

McDonough, C., Song, L., Hirsh-Pasek, K., Golinkoff, R. M., \& Lannon, R. (2011). An image is worth a thousand words: Why nouns tend to dominate verbs in early word learning. Developmental Science, 14, 181-189.

McKeown, M. G., \& Beck, I. L. (2014). Effects of vocabulary instruction on language processing: Comparing two approaches. Early Childhood Research Quarterly, 29, 520-530. http://dx.doi.org/10.1016/j.ecresq.2014.06.002

McLeod, A. N., \& McDade, H. L. (2011). Preschoolers' incidental learning of novel words during storybook reading. Communication Disorders Quarterly, 32(4), 256-266. http://dx.doi.org/10.1177/1525740109354777

McMullen, E., \& McMullen, N. (1990). Dragon for breakfast. Minneapolis: Carolrhoda Books, Inc

Mol, S. E., Bus, A. G., de Jong, M. T., \& Smeets, D. J. H. (2008). Added value of dialogic parent-child book reading: A meta-analysis. Early Education and Development, 19(1), 7-26. http://dx.doi.org/10.1080/10409280701838603

Mol, S. E., Bus, A. G., \& de Jong, M. T. (2009). Interactive book reading in early education: A tool to stimulate print knowledge as well as oral language. Review of Educational Research, 79(2), 979-1007. http://dx.doi.org/10.3102/ 0034654309332561 
Montag, J., Jones, M., \& Smith, L. (2015). The words children hear: Picture books and the statistics for language learning. Psychological Science, 29, 1489-1496. http://dx.doi.org/10.1177/0956797615594361

Munson, B., Kurtz, B. A., \& Windsor, J. (2005). The influence of vocabulary size, phonotactic probability, and wordlikeness on nonword repetitions of children with and without specific language impairment. Journal of Speech Language and Hearing Research, 48(5), 1033-1047. http://dx.doi.org/10.1044/10924388(2005/072)

Murphy, K. A., \& Farquharson, K. (2016). Investigating profiles of lexical quality in preschool and their contribution to first grade reading. Reading and Writing, 29(9), 1745-1770. http://dx.doi.org/10.1007/s11145-016-9651-y

NCES. (2015). The nation's report card: 2015 mathematics and reading assessments. Retrieved from http://www.nationsreportcard.gov/reading_math_2015/ \#reading/groups? grade $=4$.

NICHD ECCRN. (2005). Pathways to reading: The role of oral language in the transition to reading. Developmental Psychology, 41(2), 428-442. http://dx.doi org/10.1037/0012-1649.41.2.428

Nation, K., \& Snowling, M. J. (2004). Beyond phonological skills: Broader language skills contribute to the development of reading. Journal of Research in Reading, 27(4), 342-356. http://dx.doi.org/10.1111/j.1467-9817.2004.00238.x

Nation, I. S. P. (2013). Learning vocabulary in another language (2nd ed.). Cambridge: Cambridge University Press.

National Early Literacy Panel. (2009). Developing early literacy: Report of the national early literacy panel. Jessup, Maryland: National Institute for Literacy.

Neuman, S. B., \& Dwyer, J. (2011). Developing vocabulary and conceptual knowledge for low-income preschoolers: A design experiment. Journal of Literacy Research, 43(2), 103-129. http://dx.doi.org/10.1177/ 1086296X11403089

Neuman, S. B., Newman, E. H., \& Dwyer, J. (2011). Educational effects of a vocabulary intervention on preschoolers' word knowledge and conceptual: A cluster-randomized trial. Reading Research Quarterly, 46(3), 249-272. http://dx. doi.org/10.1598/RRO 46.3.3

Oetting, J. B., Rice, M. L., \& Swank, L. K. (1995). Quick incidental learning (quil) of words by school-age-children with and without sli. Journal of Speech and Hearing Research, 38(2), 434-445. http://dx.doi.org/10.1044/jshr.3802.434

Ouellette, G. P. (2006). What's meaning got to do with it: The role of vocabulary in word reading and reading comprehension. Journal of Educational Psychology, 98(3), 554-566. http://dx.doi.org/10.1037/0022-0663.98.3.554

Penno, J. F., Wilkinson, I. A. G., \& Moore, D. W. (2002). Vocabulary acquisition from teacher explanation and repeated listening to stories: Do they overcome the Matthew Effect? Journal of Educational Psychology, 94(1), 23-33.

Perfetti, C., \& Stafura, J. (2014). Word knowledge in a theory of reading comprehension. Scientific Studies of Reading, 18(1), 22-37. http://dx.doi.org/10. 1080/10888438.2013.827687

Perfetti, C. (2007). Reading ability: Lexical quality to comprehension. Scientific Studies of Reading 11(4), 357-383.

Peterson, C., Jesso, B., \& McCabe, A. (1999). Encouraging narratives in preschoolers: An intervention study. Journal of Child Language, 26, 49-67. http://dx.doi.org/ $10.1017 / \mathrm{s} 0305000998003651$

Preacher, K. J., Curran, P. J., \& Bauer, D. J. (2006). Computational tools for probing interactions in multiple linear regression, multilevel modeling, and latent curve analysis. Journal of Educational and Behavioral Statistics, 31(4), 437-448. http://dx.doi.org/10.3102/10769986031004437

Proctor, C. P., Silverman, R. D., Harring, J. R., \& Montecillo, C. (2012). The role of vocabulary depth in predicting reading comprehension among english monolingual and spanish-english bilingual children in elementary school. Reading and Writing, 25(7), 1635-1664. http://dx.doi.org/10.1007/s11145-0119336-5

Raudenbush, S. W., \& Bryk, A. S. (2002). Hierarchical linear models: Applications and data analysis methods (2nd ed.). Thousand Oaks: Sage Publications.

Robbins, C., \& Ehri, L. C. (1994). Reading storybooks to kindergartners helps them learn new vocabulary words. Journal of Educational Psychology, 86(1), 54-64. http://dx.doi.org/10.1037/0022-0663.86.1.54

Roskos, K., \& Burstein, K. (2011). Assessment of the design efficacy of a preschool vocabulary instruction technique. Journal of Research in Childhood Education, 25, 268-287. http://dx.doi.org/10.1080/02568543.2011.580041

Roskos, K., Ergul, C., Bryan, T., Burstein, K., Christie, J., \& Han, M. (2008). Who's learning what words and how fast? Preschoolers' vocabulary growth in an early literacy program. Journal of Research in Childhood Education, 22(3), 275-290. http://dx.doi.org/10.1080/02568540809594627
Sénéchal, M., Thomas, E., \& Monker, J. A. (1995). Individual difference in 4-year-old children's acquisitin of vocabulary during storybook reading. Journal of Educational Psychology, 87(2), 218-229. http://dx.doi.org/10.1037//0022-0663. 87.2.218

Sénéchal, M. (1997). The differential effect of storybook reading on preschoolers' acquisition of expressive and receptive vocabulary. Journal of Child Language, 24(01),123-138. http://dx.doi.org/10.1017/s0305000996003005

Schickedanz, J., \& Dickinson, D. K. (2005). Opening the world of learning: A comprehensive literacy program. Parsippany, NJ: Pearson Early Learning.

Silverman, R., \& Crandell, J. D. (2010). Vocabulary practices in prekindergarten and kindergarten classrooms. Reading Research Quarterly, 45(3), 318-340. http:// dx.doi.org/10.1598/rrq.45.3.3

Silverman, R. D., \& Hartranft, A. M. (2015). Developing vocabulary and oral language in young children. New York: Guilford Press.

Snow, C. E., Cancino, H., De Temple, J., \& Schley, S. (1991). Giving formal definitions: A linguistic or metalinguistic skill? In E. Bialystock (Ed.), Language processing in bilingual children (pp. 90-112). Cambridge: Cambridge University Press.

Stahl, S. A., \& Fairbanks, M. M. (1986). The effects of vocabulary instruction: A model-based meta-analysis. Review of Educational Research, 56(1), 72-110. http://dx.doi.org/10.3102/00346543056001072

Stanovich, K. E. (1986). Matthew Effects in reading: Some consequences of individual differences in the acquisition of literacy. Reading Research Quarterly. $21,360-407$.

Storch, S. A., \& Whitehurst, G. J. (2002). Oral language and code-related precursors to reading: Evidence from a longitudinal structural model. Developmental Psychology, 38, 934-947. http://dx.doi.org/10.1037//0012-1649.38.6.934

Tannenbaum, K. R., Torgesen, J. K., \& Wagner, R. K. (2006). Relationships between word knowledge and reading comprehension in third-grade children. Scientific Studies of Reading, 10(4), 381-398. http://dx.doi.org/10.1207/ s1532799xssr1004_3

Tuckwiller, E. D., Pullen, P. C., \& Coyne, M. D. (2010). The use of the regression discontinuity design in tiered intervention research: A pilot study exploring vocabulary instruction for at-risk kindergarteners. Learning Disabilities Research E Practice, 25(3), 137-150. http://dx.doi.org/10.1111/j.1540-5826. 2010.00311.x

van Kleeck, A., Vander Woude, J., \& Hammett, L. (2006). Fostering literal and inferential language skills in head start preschoolers with language impairment using scripted book-sharing discussions. American Journal of Speech-Language Pathology, 15(1), 85-95. http://dx.doi.org/10.1044/1058-0360(2006/009)

Waddell, M., \& Oxenbury, H. (1991). Farmer duck. Cambridge, MA: Candlewick Press.

Walker, D., Greenwood, C., Hart, B., \& Carta, J. (1994). Prediction of school outcomes based on early language production and socioeconomic factors. Child Development, 65, 606-621. http://dx.doi.org/10.2307/1131404

Wasik, B. A., Bond, M. A., \& Hindman, A. (2006). The effects of a language and literacy intervention on head start children and teachers. Journal of Educational Psychology, 98(1), 63-74. http://dx.doi.org/10.1037/0022-0663.98.1.63

Wasik, B. A., Hindman, A. H., \& Snell, E. K. (2016). Book reading and vocabulary development: A systematic review. Early Childhood Research Quarterly, 37, 39-57. http://dx.doi.org/10.1016/j.ecresq.2016.04.003

Weisberg, D. S., Hirsh-Pasek, K., Golinkoff, R., Nicolopoulou, A., \& Dickinson, D. K. (2015). Shovels and swords: How realistic and fantastical themes affect children's word learning. Cognitive Development, 35, 1-14. http://dx.doi.org/10 1016/j.cogdev.2014.11.001

Weizman, Z. O., \& Snow, C. E. (2001). Lexical output as related to children's vocabulary acquisition: Effects of sophisticated exposure and support for meaning. Developmental Psychology, 37(2), 265-279. http://dx.doi.org/10.1037 0012-1649.37.2.265

Yuan, S., \& Fisher, C. (2009). "Really? She blicked the baby?” Two-year-olds learn combinatorial facts about verbs by listening. Psychological Science, 20(5), 619-626. http://dx.doi.org/10.1111/j.1467-9280.2009.02341.x

Zucker, T. A., Justice, L. M., Piasta, S. B., \& Kaderavek, J. N. (2010). Preschool teachers' literal and inferential questions and children's responses during whole-class shared reading. Early Childhood Research Quarterly, 25(1), 65-83. http://dx.doi.org/10.1016/j.ecresq.2009.07.001

Zucker, T. A., Cabell, S. Q., Justice, L. M., Pentimonti, J. M., \& Kaderavek, J. N. (2013). The role of frequent, interactive prekindergarten shared reading in the longitudinal development of language and literacy skills. Developmental Psychology, 49(8), 1425-1439. http://dx.doi.org/10.1037/a0030347 